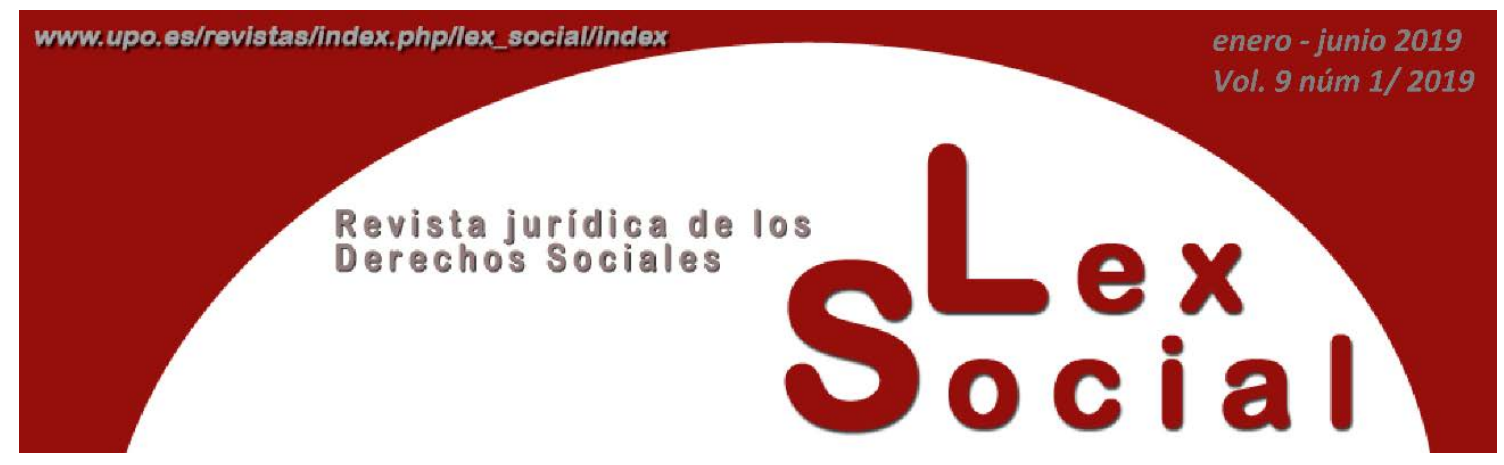

\title{
EL CONSTITUCIONALISMO SOCIAL Y LOS OBJETIVOS DE DESARROLLO SOSTENIBLE (ODS)
}

\section{SOCIAL CONSTITUTIONALISM AND THE SUSTAINABLE DEVELOPMENT GOALS (SDG)}

\author{
LUIS JIMENA QUESADA* \\ Catedrático de Derecho Constitucional \\ Universitat de València
}

Artículo recibido el 28 de febrero de 2019

Artículo aceptado el 7 de marzo de 2019

\section{RESUMEN}

El Derecho Constitucional, y especialmente el Constitucionalismo Social, no puede quedar al margen del análisis de los Objetivos de Desarrollo Sostenible (ODS). En efecto, la Agenda 2030 constituye una Agenda de Constitucionalismo Global de naturaleza básicamente social. Desde esta perspectiva, los ODS integran una especie de Pilar Universal de Derechos Sociales y, como consecuencia, inspiran el modelo social europeo y la realización de los derechos sociales en el orden constitucional nacional. Con tales premisas, el autor somete a análisis el valor interpretativo y la efectividad de los ODS en el sistema constitucional español a través de ilustraciones de la práctica legislativa, ejecutiva y judicial. Sin embargo, como retos de constitucionalismo multinivel, los ODS conforman no sólo una agenda para los poderes públicos, sino asimismo un compromiso para el conjunto de la ciudadanía y del tercer sector, sin olvidar el compromiso de los demás actores

\footnotetext{
* El presente trabajo se ha elaborado en el marco del Grupo de Investigación "Derechos Humanos y Carta Social Europea" (referencia: GIUV2013-148), así como de la "Red temática en Justicia constitucional y diálogo judicial” (acrónimo: JUDICO) del Ministerio de Economía y Competitividad (DER2016-81801REDT).
} 
de la sociedad, incluyendo la Academia.

Palabras Clave: Constitucionalismo Global, Pilar Universal de Derechos Sociales, Protección Multinivel, Sentimiento Constitucional, Conciencia Internacional.

\begin{abstract}
Constitutional Law, and Social Constitutionalism in particular, cannot avoid the analysis of the Sustainable Development Goals (SDG). Indeed, the 2030 Agenda constitutes an Agenda for Global Constitutionalism of an essentially social nature. From this perspective, the SDG integrate a kind of Universal Pillar of Social Rights and, as a result, inspire both the European social model and the realization of social rights in the national constitutional order. With these premises, the author analyzes the interpretive value and the effectiveness of the SDG in the Spanish constitutional system through illustrations of legislative, executive and judicial practice. However, as many other multi-level constitutionalism challenges, the SDG make up not only an agenda for the public authorities, but also a commitment for the whole citizenship and the third sector, without forgetting the commitment of the other relevant societal actors, including the academia.
\end{abstract}

KEY WORDS: Increase Global Constitutionalism, Universal Pillar of Social Rights, Multi-level Protection, Constitutional Feeling, International Conscience.

SUMARIO

I. Consideraciones introductorias: la convergencia de designios constitucionales y universales.

II. Cuestiones procedimentales: el valor constitucional interpretativo de los ODS.

III. Cuestiones sustanciales: los ODS y la efectividad de los derechos sociales:

1. Aproximación general.

2. Enfoque concreto.

3. Ilustraciones de implementación en España.

IV. Consideraciones finales: Ios ODS como reto del constitucionalismo global y multinivel. 


\section{Consideraciones introductorias: la convergencia de designios constitucionales y universales}

La Agenda 2030 para el Desarrollo Sostenible fue objeto de adopción mediante Resolución 70/1 de 25 de septiembre de 2015, en el seno de la Asamblea General de la ONU, por los Jefes de Estado y de Gobierno y Altos Representantes, reunidos en la Sede de las Naciones Unidas en Nueva York del 25 al 27 de septiembre de 2015, coincidiendo con el septuagésimo aniversario de la Organización. Mediante esa nueva y ambiciosa Agenda se acordaban diecisiete "Objetivos de Desarrollo Sostenible” (ODS) y ciento sesenta y nueve metas de alcance mundial. En realidad, los ODS constituyen una Agenda cotidiana de desarrollo constitucional en cada país (epígrafe I), que debe inspirar la dinamización de la "parte orgánica” (epígrafe II) y la vigencia de la "parte dogmática” (epígrafe III) en el contexto de un movimiento creciente de internacionalización del Derecho constitucional y, correlativamente, constitucionalización del Derecho internacional, configurándose consiguientemente los ODS como reto del constitucionalismo global y multinivel (epígrafe IV). Por lo tanto, es insoslayable estar atentos desde el Derecho Constitucional a la globalización (política, económica, financiera, cultural) ${ }^{1}$.

En efecto, si observamos el contenido del Preámbulo de la Constitución española de 1978 (CE), comprobamos que los designios en él propugnados presentan una ostensible sintonía con los designios formulados en el Preámbulo y la Declaración que encabezan los ODS. En concreto, los designios constitucionales de "establecer la justicia, la libertad y la seguridad y promover el bien de cuantos la integran”, de "garantizar la convivencia democrática” y “un orden económico y social justo”, de “consolidar un Estado de Derecho", de proteger "el ejercicio de los derechos humanos", de "promover el progreso de la cultura y de la economía para asegurar a todos una digna calidad de vida”, de “establecer una sociedad democrática avanzada” y de “colaborar en el fortalecimiento de unas relaciones pacíficas y de eficaz cooperación entre todos los pueblos de la Tierra”, tienen su trasunto en los designios universales de la Agenda 2030.

Particularmente, el Preámbulo de la Agenda 2030 se abre con un llamamiento a la consecución de la "prosperidad", al fortalecimiento de "la paz universal dentro de un concepto más amplio de la libertad” y a "la erradicación de la pobreza” como parte de un plan que "será implementado por todos los países y partes interesadas mediante una alianza de colaboración” que dé pie a una equitativa distribución del bienestar². Del

\footnotetext{
1 SPADARO, A.: Dai diritti 'individuali' ai doveri 'globali'. La giustizia distributiva internazionale nell'età della globalizzazione, Soveria Mannelli, Rubbettino, 2005, p. 69.

${ }^{2}$ Las claves de esa distribución han sido sintetizadas por SACHS, J.: La era del desarrollo sostenible, Deusto, Ediciones Deusto, 2014, p. 30-31: "Existen al menos cinco tipos de problemas en relación con la distribución del bienestar. El primero es la pobreza extrema. ¿Existen aún personas en situación de pobreza extrema en un contexto de abundancia? El segundo es la desigualdad. ¿Existe una gran distancia entre los ricos y los pobres? El tercero es la movilidad social. ¿Puede una persona pobre aspirar al éxito económico en el futuro, o existen barreras prácticas al ascenso social? El cuarto es la discriminación. ¿Hay personas
} 
mismo modo, "también se pretende hacer realidad los derechos humanos de todas las personas y alcanzar la igualdad entre los géneros y el empoderamiento de todas las mujeres y niñas”. A continuación, el Preámbulo de la Agenda 2030 incide en "poner fin a la pobreza y el hambre" para favorecer que "todos los seres humanos puedan realizar su potencial con dignidad e igualdad y en un medio ambiente saludable” que satisfaga "las necesidades de las generaciones presentes y futuras", así como que "puedan disfrutar de una vida próspera y plena” en armonía con "el progreso económico, social y tecnológico". Y se enfatizan asimismo los ideales de paz ("propiciar sociedades pacíficas, justas e inclusivas que estén libres del temor y la violencia”) y de “alianza mundial” que "se base en un espíritu de mayor solidaridad mundial y se centre particularmente en las necesidades de los más pobres y vulnerables, con la colaboración de todos los países, todas las partes interesadas y todas las personas", todo ello con el objetivo último de mejorar "notablemente las condiciones de vida de todas las personas" y así "nuestro mundo se transformará en un lugar mejor”.

Si efectuamos un primer parangón entre los designios consignados en el Preámbulo de la CE y en el de la Agenda 2030, constatamos que ambos comparten apelaciones más o menos explícitas a la libertad y a la seguridad (a vivir sin temor ni violencia), a la dignidad, al progreso o a la convivencia pacífica. Es cierto que el Preámbulo constitucional no alude explícitamente a la igualdad (ni, por ende, "entre géneros”), a la solidaridad y la erradicación de la pobreza, o al medio ambiente; en cambio, cabría entender compensadas dichas omisiones por el amplio espectro del "orden económico y social justo” del Preámbulo y, en cualquier caso, la igualdad y la solidaridad ocupan un lugar preeminente entre los valores y principios constitucionales del Título preliminar (arts. 1.1, 2 ó 9.2 CE), mientras que diversas disposiciones constitucionales del Título I ofrecen base habilitante para la lucha contra la pobreza y la exclusión social (arts. 41 ó 47 CE) o la protección del medio ambiente (art. $45 \mathrm{CE}$ ). En el supuesto de la solidaridad, que ya fue teorizada como eje del Derecho constitucional por Duguit ${ }^{3}$, ha sido asimismo catalogada como concepto identificador del constitucionalismo social ${ }^{4}$. De

en situación de desventaja dentro del grupo en razón de su identidad, como por ejemplo las mujeres, las minorías raciales y religiosas, o las poblaciones indígenas? El quinto es la cohesión social. ¿Está minada la sociedad por la desconfianza, los antagonismos, el cinismo y la ausencia de códigos morales compartidos? El desarrollo sostenido se enfrenta también a esas cuestiones y promueve que las sociedades se pongan por objetivo la erradicación de la pobreza extrema; la reducción de las grandes desigualdades entre ricos y pobres; un elevado nivel de movilidad social y la existencia de buenas perspectivas de vida para niños nacidos en situación de pobreza; la ausencia de discriminación por razones de género, raza, religión o etnia; y la promoción de la confianza social, la solidaridad mutua, los valores sociales y la cohesión. Podemos resumir todos estos objetivos con la expresión «inclusión social»”.

${ }^{3}$ Véase DUGUIT, L.: Manual de Derecho Constitucional, Granada, Comares, 1921 (edición preparada por MONEREO PÉREZ, J.L., y CALVO GONZÁLEZ, J.), 2005. Léase asimismo AGUILERA PORTALES, R., y ESPINO TAPIA, D.R., "Repensar a Léon Duguit ante la actual crisis del Estado social”, Universitas. Revista de Filosofía, Derecho y Política, n 12, 2010, pp. 49-71.

${ }^{4}$ Señaladamente, TAJADURA TEJADA, J. "El principio de solidaridad como fundamento común de los Estados sociales europeos”, en TEROL BECERRA, M., y JIMENA QUESADA, L. (Dirs.): Tratado sobre protección de derechos sociales, Valencia, Tirant lo Blanch, 2014, p. 90, así como TORRES DEL MORAL, 
igual manera, con acierto se ha postulado a la luz de la Agenda 2030 que el desarrollo sostenible, a través de los componentes sociales y solidarios, tiene una "existencia constitucional europea” que debe marcar el nuevo modelo de gobernanza de la UE apostando más marcadamente por la dimensión social ${ }^{5}$.

Por su lado, aunque en el Preámbulo de la Agenda 2030 no se haga referencia expresa a las ideas de Estado de Derecho y de sociedad o convivencia democrática, la Declaración subsiguiente (a modo de "Título preliminar universal”) sí se hace eco de ellas en su punto 9, al apostar por "un mundo en que la democracia, la buena gobernanza y el estado de derecho, junto con un entorno nacional e internacional propicio, sean los elementos esenciales del desarrollo sostenible, incluidos el crecimiento económico sostenido e inclusivo, el desarrollo social, la protección del medio ambiente y la erradicación de la pobreza y el hambre”. Como fácilmente se colige, este punto 9 alberga una especie de “formulación universal” del Estado social y democrático de Derecho análoga a la que recoge el art. 1.1 CE.

Por añadidura, esa fórmula integrada se ve a su vez imbuida de manera transversal por el enfoque al que se apela en el último párrafo del Preámbulo de la Agenda 2030, cuando se sostiene en él que "los Objetivos y las metas son de carácter integrado e indivisible y conjugan las tres dimensiones del desarrollo sostenible: económica, social y ambiental”. Podría decirse que esas tres dimensiones de los ODS se hacen eco de los tres vectores esenciales del constitucionalismo social actual.

Ilustremos dicha afirmación en clave de constitucionalismo comparado por referencia a nuestros dos países vecinos. Así, el Consejo previsto en el art. 131.2 CE (denominado "Consejo económico y social" en su ley de desarrollo ${ }^{6}$ ) tiene en su homólogo francés la denominación más reciente de “Consejo económico, social y

A.: "El Estado social y la evolución del constitucionalismo social”, en TEROL BECERRA, M., y JIMENA QUESADA, L. (Dirs.): Tratado sobre protección de derechos sociales, op. cit., p. 55.

${ }^{5}$ SÁNCHEZ GALERA, M.D.: "Sustainable development: The 'hedgehog' or the 'fox' of the European integration dream? A closer look to its social dimension”, en MASALA, P. (Ed.): La Europa social: alcances, retrocesos y desafíos para la construcción de un espacio jurídico de solidaridad, Madrid, Centro de Estudios Políticos y Constitucionales, 2018, pp. 363-396. Y no debe perderse de vista el fondo del problema, como ya apuntó ARAGÓN REYES, M.: Libertades económicas y Estado social, Madrid, McGrawHill, 1995, p. 135: "Sostener que el mercado, a largo plazo, produce igualdad social no es sólo predicar algo no enteramente demostrado (a veces no se llama la atención suficientemente acerca de la dimensión idealista del liberalismo económico radical), sino también exigir unos sacrificios temporales que repugnan a la concepción ética (o de solidaridad) que está en la misma base del Estado social, aparte de que ese sacrificio sea difícil de cohonestar con las exigencias de integración política que el Estado (todo Estado) está llamado a desempeñar. El problema se complica cuando se introduce en él la dimensión internacional”. ${ }^{6}$ Ley 21/1991, de 17 de junio, de Creación del Consejo Económico y Social. En su Exposición de Motivos puede leerse: "El órgano que se crea, cuya denominación es la de Consejo Económico y Social, refuerza la participación de los agentes económicos y sociales en la vida económica y social, reafirmando su papel en el desarrollo del Estado Social y Democrático de Derecho". En el mismo sentido, por ejemplo, la Ley 2/2001, de 27 de marzo, del Consejo Económico y Social de la Comunidad Autónoma del Principado de Asturias resalta en su Preámbulo que su marco regulador se inspira "en los principios y directrices que informan, en otras Comunidades Autónomas y también a nivel estatal y europeo, el tratamiento legal de los Consejos Económicos y Sociales, cuya importancia no ha dejado de crecer, y debe ser justamente resaltada, en el contexto del Estado social y democrático de Derecho”. 
ambiental" 7 , el cual es objeto de discusión a propósito de su papel actual y, de hecho, no es ajeno a las propuestas de reforma institucional del Presidente de la República Macron ${ }^{8}$. Por su parte, en el caso de Italia, la propuesta "Renzi” de reforma constitucional incluía la supresión del “Consejo Nacional de la Economía y del Trabajo” establecido mediante la Constitución de 1947 (art. 99), pero como medida de reforma constitucional "anticrisis” no prosperó ${ }^{9}$ (a diferencia de medidas parecidas en el ámbito regional español ${ }^{10}$ ) y, con ello, no se asestó un golpe a una institución de raigambre en el constitucionalismo social italiano de la segunda posguerra ${ }^{11}$; ahora bien, esa propuesta de supresión se ha retomado en 2018 en las ulteriores propuestas de reforma por parte del Gobierno italiano ${ }^{12}$.

\section{Cuestiones procedimentales: el valor constitucional interpretativo de los ODS}

En línea coherente con la reseñada convergencia de los designios constitucionales (expresados en el Preámbulo de la Carta Magna española de 1978) y universales (incluidos en el Preámbulo y Declaración de la Resolución de la ONU de 2015 relativa a la Agenda 2030), y sin pretender en esta sede efectuar un nuevo estudio sobre el alcance

\footnotetext{
${ }^{7}$ Efectivamente, la denominación inicial en la Constitución vigente de 1958 de la Quinta República era "Consejo Económico y Social" (el aditamento "Social" era una novedad importante con respecto al "Consejo Económico" de la Constitución anterior de 1946 de la Cuarta República), pero mediante la Ley constitucional $n^{\circ}$ 2008-724 de 23 de julio de 2008 de modernización de las instituciones de la V ${ }^{a}$ República, entre otras medidas, se añadió el adjetivo "ambiental" (arts. 32 a 35). En cada región francesa existe asimismo con análoga denominación, desde 2010, un "Consejo económico, social y ambiental regional”. ${ }^{8}$ BARDOU, F.: “À quoi sert (en théorie) le Conseil économique, social et environnemental?”, Libération, 6 juillet 2017 (https://www.liberation.fr/france/2017/07/06/a-quoi-sert-en-theorie-le-conseil-economiquesocial-et-environnemental_1581769).

${ }^{9}$ Se trataba del Proyecto de Ley Constitucional que introducía Disposiciones para la superación del bicameralismo paritario, la reducción del número de los parlamentarios, la contención de los costes de funcionamiento de las instituciones, la supresión del CNEL (Consejo Nacional de la Economía y del Trabajo) y la revisión del título V de la Parte II de la Constitución [Disposizioni per il superamento del bicameralismo paritario, la riduzione del numero dei parlamentari, il contenimento dei costi di funzionamento delle istituzioni, la soppressione del CNEL (Consiglio nazionale dell'economia e del lavoro) e la revisione del Titolo V della parte II della Costituzione]. El 4 de diciembre de 2016 se votó en referéndum contra esa propuesta de reforma (casi 60\% el “no"), con dimisión del Primer Ministro Matteo Renzi.

${ }^{10}$ A título de ejemplo, con teórica motivación en la austeridad y la racionalización del gasto, véase la Ley 13/2011, de 3 de noviembre, de supresión del Consejo Económico y Social de Castilla-La Mancha.

${ }^{11}$ Véase RUINI, M.: “Che cos'è il CNEL”, en RUINI, M.: Il Consiglio Nazionale dell'Economia e del Lavoro. Scritti e discorsi (1947-1959), Roma, Associazione dei già Consiglieri, CNEL, 2013, p. 73 (http://www.articolo99.it/files/Meuccio-Ruini---Consiglio-Nazionale-dell-Economia-e-del-Lavoro.pdf).

${ }^{12}$ Véase el documento "Iniziative di riforme costituzionale", Camera dei deputati, Servizio Studi, XVIII Legislatura, 7 febbraio 2019, p. 2 (http://www.camera.it/temiap/documentazione/temi/pdf/1104514.pdf); este documento se remite al documento referente al programa de reformas del Gobierno italiano contenido en la Nota di aggiornamento del Documento di economia e finanza 2018, Roma, Ministerio dell'Economia e delle Finanze, 2018, p. 112 (http://www.mef.gov.it/inevidenza/documenti/NADEF 2018.pdf).
} 
de los Preámbulos constitucionales ${ }^{13}$ (o internacionales mutatis mutandis) ${ }^{14}$, el discurso argumental lógico impone ponderar el alcance orientativo o el valor interpretativo de los ODS en el ordenamiento jurídico español, en aras de verificar la influencia de esos ODS en las acciones de los poderes públicos, de la ciudadanía o de las organizaciones de la sociedad civil en el ámbito nacional.

A tal efecto, sobre partir de la naturaleza programática o de soft-law de la Resolución de la Asamblea General aprobatoria de los ODS, no resulta impertinente ponderar la proyección del propio Preámbulo constitucional con la del mandato del art. 9.1 CE de sujeción a la Constitución y “al resto del ordenamiento jurídico” (en el que se integran esas Resoluciones internacionales con su mencionado carácter no vinculante) y del paralelo mandato del art. 9.2 CE (en clave de promoción material de la libertad y la igualdad), así como del mandato interpretativo de índole internacional establecido en el art. 10.2 y del mandato orientador de la praxis (más específico en el terreno del constitucionalismo social) del art. 53.3 CE, sin perjuicio evidentemente de cláusulas sustanciales más singulares relacionadas con el mandato dirigido a los poderes públicos en el terreno de la salud (art. 43 CE), el medio ambiente (art. 45) o la vivienda (art. 47 $\mathrm{CE})$.

Con tales parámetros, nuestra jurisprudencia constitucional inicial aportó pronunciamientos de gran interés, especialmente la STC 64/1982, de 4 de noviembre, que al interpretar el art. $45 \mathrm{CE}$, enfatiza las obligaciones de respeto del medio ambiente derivadas de esa misma disposición conjuntamente con el mandato del art. 53.3 CE, recordando que el art. 45 CE "recoge la preocupación ecológica surgida en las últimas décadas en amplios sectores de opinión que ha plasmado también en numerosos documentos internacionales (...) todo ello para el mejor desarrollo de la persona y para asegurar una mejor calidad de la vida”. Además, se refuerza el alcance del art. 45 CE a la luz del Preámbulo constitucional, al recordarse que "la calidad de vida que cita el art. 45 y uno de cuyos elementos es la obtención de un medio ambiente adecuado para

\footnotetext{
${ }^{13}$ Entre otros, ya TAJADURA TEJADA, J.: El Preámbulo constitucional, Granada, Comares, 1997, p. 29: "los textos preambulares pueden desempeñar un papel fundamental para la interpretación tanto sicológica como teleológica de cualquier texto normativo y, por supuesto, la Constitución”; y, del mismo autor, “Veinticinco años de Preámbulo constitucional”, Revista de Derecho Político, no 58-59, 2003/2004, pp. 2946. Con anterioridad, COLOMER VIADEL, A.: "Las normas constitucionales de carácter programático y los procedimientos para conseguir su eficacia”, Cuadernos Constitucionales de la Cátedra Fadrique Furió Ceriol, n 9-10, 1995, pp. 19-31. Y, más recientemente, RUIPÉREZ ALAMILLO, J.: “Entrevista”, en PALOMINO MANCHEGO, J.F. (Coord.): El Preámbulo constitucional dialogado, Lince, Universidad Inca Garcilaso de la Vega, 2018, p. 183: a la hora de identificar "los principios y valores que por existir realmente en la sociedad fueron consagrados por el legislador constituyente y, que, por ello mismo, deben presidir la vida presente y futura de la comunidad política”, no existe una gran diferencia "entre el contenido literal del preámbulo constitucional y el del articulado concreto del Código Constitucional, el del resto de las normas del Derecho Constitucional material y el de la legislación ordinaria que desarrolla las anteriores", pues en todo caso la interpretación "ha de hacerse a la luz de lo establecido por el poder constituyente originario en el texto preambular".

${ }^{14}$ Véase el art. 31 (regla general de interpretación) del Convenio de Viena de 1969 sobre el Derecho de los Tratados, en cuyo apartado 1 se manda "tener en cuenta su objeto y fin”, mencionándose a renglón seguido en el apartado 2 “su preámbulo y anexos”.
} 
promoverla está proclamada en el preámbulo de la Constitución y recogida en algún otro artículo como el 129.1” (FJ 3).

Esa línea jurisprudencial se ha ido consolidando en pronunciamientos posteriores, siendo uno de los más significativos la STC 102/1995, en el marco de un conflicto competencial sobre materia ambiental en el que, precisamente remitiéndose a la STC 64/1982, se trae a colación otro instrumento no vinculante de Naciones Unidas configurado como uno de los precedentes de la Agenda 2030. Así, en el FJ 4 de dicha STC 102/1995 se sostiene que, para evaluar el significado constitucional del medio ambiente, «hemos de remontarnos a la calidad de vida como aspiración situada en primer plano por el Preámbulo de la Constitución, que en principio parece sustentarse sobre la cultura y la economía, aun cuando en el texto articulado se ligue por delante a la utilización racional de los recursos naturales y por detrás al medio ambiente, con el trasfondo de la solidaridad colectiva. En suma, se configura un derecho de todos a disfrutarlo y un deber de conservación que pesa sobre todos, más un mandato a los poderes públicos para la protección (art. 45 C.E.). En seguida, la conexión indicada se hace explícita cuando se encomienda a los Poderes públicos la función de impulsar y desarrollar se dice, la actividad económica y mejorar así el nivel de vida, ingrediente de la calidad si no sinónimo, con una referencia directa a ciertos recursos (la agricultura, la ganadería, la pesca) y a algunos espacios naturales (zonas de montaña) (art. 130 C.E.), lo que nos ha llevado a resaltar la necesidad de compatibilizar y armonizar ambos, el desarrollo con el medio ambiente (STC 64/1982). Se trata en definitiva del "desarrollo sostenible", equilibrado y racional, que no olvida a las generaciones futuras, alumbrado el año 1987 en el llamado Informe Bruntland, con el título "Nuestro futuro común" encargado por la Asamblea General de las Naciones Unidas» ${ }^{15}$.

Con el mismo espíritu, un pronunciamiento precedente, que también se hizo eco explícito de la STC 64/1982, se recogió en la STC 329/1993 de 12 de noviembre ${ }^{16}$, que abordó igualmente la problemática de la coordinación competencial en materia ambiental realzando nuevamente el valor del Preámbulo constitucional y de textos internacionales (vinculantes y programáticos) en la materia ${ }^{17}$. En otras sentencias constitucionales

\footnotetext{
15 El énfasis es mío.

${ }^{16}$ En parecido sentido, la STC 106/2014, de 24 de junio, en cuyo FJ 7 se efectúa un reenvío explícito a las SSTC 64/1982 y 329/1993.

${ }^{17}$ En el FJ 4 de dicha STC 329/1993, se pone el énfasis en «la garantía del derecho de todos a disfrutar de un medio ambiente adecuado para el desarrollo de la persona (art. 45.1 C.E.) que se refiere en particular a la prevención de la contaminación atmosférica, [y que] en los últimos años se ha manifestado, entre otros instrumentos internacionales, en el Convenio de Viena de 22 de marzo de 1985 y su Protocolo adicional, hecho en Montreal el 16 de septiembre de 1987, para la protección de la capa de ozono, así como en la Declaración de La Haya de 11 de marzo de 1989. Siendo de señalar que tanto en estos instrumentos internacionales como en el art. 45 C.E., la protección del medio ambiente tiene como objetivo final y está íntimamente unida a "la protección de la salud de las personas" (art. $130 \mathrm{R}$ del Tratado Constitutivo de la Comunidad Europea), pues como se ha dicho en la STC 64/1982, (fundamento jurídico $1^{\circ}$ ) la “calidad de vida” que cita el art. 45 C.E. y uno cuyos elementos es la obtención de un medio ambiente adecuado para promoverla "está proclamada en el preámbulo de la Constitución y recogida en algún otro artículo como el 129.1”.»
} 
tampoco ha estado exento el significado interpretativo del Preámbulo constitucional: en materia de patrimonio cultural y pluralismo lingüístico para "proteger las diversas culturas, tradiciones y lenguas de los pueblos de España, [que] encuentra una proyección inmediata en el articulado de nuestro texto constitucional” (STC 134/1997, de 17 de julio, FJ 2); o en materia de inmunidad diplomática para resaltar la voluntad de la Nación española de "colaborar en el fortalecimiento de unas relaciones pacíficas y de eficaz cooperación entre todos los pueblos de la Tierra” (STC 140/1995, de 28 de septiembre, FJ 8); para realzar el establecimiento de una "sociedad democrática avanzada”, "como reza el Preámbulo de nuestra Constitución”, en conexión con "la inequívoca vinculación del derecho a la educación con la garantía de la dignidad humana, dada la innegable trascendencia que aquélla adquiere para el pleno y libre desarrollo de la personalidad, y para la misma convivencia en sociedad, que se ve reforzada mediante la enseñanza de los valores democráticos y el respeto a los derechos humanos”, además de subrayar el valor interpretativo de los trabajos preparatorios del art. 2 del Protocolo ${ }^{\circ} 1$ adicional al CEDH que reconoce el citado derecho a la educación (STC 236/2007, de 7 de noviembre, FJ 8); o, en materia de signos de identidad (con significación religiosa o no), que, "en tanto se configuren como tradiciones, han de gozar de la protección pretendida por el preámbulo de nuestra Constitución” (STC 34/2011, de 28 de marzo, FJ 6 in fine).

Descendiendo ahora al terreno más restringido del constitucionalismo social y los ODS, me parece inexcusable aludir conexamente al valor interpretativo que nuestra misma Jurisdicción Constitucional ha atribuido a instrumentos no vinculantes de la OIT, sin perder de vista que fue justamente en el marco de esta organización internacional en donde se mencionó por vez primera de modo explícito la dignidad de la persona como inherente a los derechos humanos (en este caso, socio-laborales), concretamente mediante la Declaración de Filadelfia de 1944 ${ }^{18}$. En tal dirección, la STC 38/1981, d 23 de noviembre (en el contexto de un recurso de amparo con origen en un procedimiento laboral de despido) sostuvo que "las Recomendaciones de la OIT, si bien, como es obvio, distintas de los Convenios, y sin alusión directa en el art. 10.2 de la Constitución, son textos orientativos, que sin eficacia vinculante pueden operar como criterios interpretativos o aclaratorios de los Convenios, carácter con el que se invocan aquí las Recomendaciones a las que hemos hecho sucinta referencia” (FJ 4) ${ }^{19}$. Por la misma senda

\footnotetext{
${ }^{18}$ La cual comporta, como se ha destacado en la doctrina, la reafirmación del trabajo digno en el escenario internacional: LEMGRUBER EBERT, P.R.: “A Constituição da OIT (1919) e a Declaração de Filadélfia (1944)”, en JANNOTTI DA ROCHA, C. et al. (Coords.): Direito internacional do trabalho: aplicabilidade e eficácia dos instrumentos internacionais de proteção ao trabalhador, São Paulo, Editora LTr, 2018, p. 302.

${ }^{19}$ Y se refuerza esa interpretación en el FJ 6 de la propia STC 38/1981: "Como ya anunciamos en otro de los fundamentos jurídicos, la protección frente a los actos de discriminación, vedados por el art. 28.1 de la Constitución en lo que es propio de la libertad sindical, alcanza subjetivamente a todos los trabajadores, aunque respecto de los cualificados por su carácter de representantes adquiera la protección un especial reforzamiento (así, Convenio de la O.I.T. -135, art. 1-) con especial proyección en materia de despido traducible, entre otras particularidades, en garantías formales y en una inversión de la opción entre readmisión o indemnización (art. 68 c) del Estatuto de los Trabajadores y arts. 212 y 213 de la Ley de Procedimiento Laboral). La no inclusión en la literalidad de los preceptos reguladores actualmente de las
} 
se encaminó la STC 41/2002, de 25 de febrero (sobre no discriminación laboral de la mujer embarazada), en cuyo FJ 3 se corrobora el valor de las Recomendaciones y las Declaraciones de la OIT como "fuente interpretativa" a la luz del art. 10.2 CE ${ }^{20}$.

A mayor abundamiento, el núcleo del constitucionalismo social que viene representado por el respeto de los derechos socio-laborales se encuentra estrechamente vinculado con las modernas tendencias de acentuación de la responsabilidad social de las empresas, en el marco de un enfoque más amplio de derechos humanos aplicable asimismo a las compañías transnacionales. Este desafío ha venido promocionándose en el ámbito universal ${ }^{21} \mathrm{y}$ regional ${ }^{22}$ a través de principios rectores sobre el respeto por las

garantías sindicales de aquellos que son candidatos, o que han sido presentados como candidatos a la elección o al nombramiento de representantes de los trabajadores, no es obstáculo a la protección frente a despidos discriminatorios, pues, además de que, como hemos dicho, alcanza a todos los trabajadores, recaba una especial atención cuando los actos que se denuncian como discriminatorios afectan a los candidatos en curso el proceso electoral y se les imputa propósitos de interferir decisivamente en la libre dotación de la representación obrera. Tal es, por otra parte, el contenido de la Recomendación de la O.I.T. -143 (III, 7.1, complementaria -con el valor que según lo que dijimos en su momento, tienen las Recomendaciones el Convenio de la O.I.T. -135-” (énfasis añadido).

${ }^{20}$ En dicho FJ 3 de la STC 41/2002 se afirma: "el examen de la normativa que ex art. 10.2 CE sirve de fuente interpretativa así lo corrobora. En efecto, prescribe el art. 5 d) del Convenio núm. 158 de la Organización Internacional del Trabajo que el embarazo no constituirá causa justificada para la terminación de la relación de trabajo. De otra parte, según el art. 4.1 de la Recomendación núm. 95, también de la OIT, el período durante el cual será ilegal para el empleador despedir a una mujer debe comenzar a contarse a partir del día en que le haya sido notificado el embarazo por medio de un certificado médico. Y al respecto la Declaración de 1975 sobre la igualdad de oportunidades y de trato para las trabajadoras, insiste en que la mujer encinta estará protegida contra todo despido por razón de su condición durante todo el período de embarazo (art. 8.1)".

${ }^{21}$ En el ámbito universal, son referencia obligada los Principios rectores sobre las empresas y los derechos humanos. Puesta en práctica del marco de las Naciones Unidas para "proteger, respetar y remediar", adoptados por el Consejo de Derechos Humanos mediante su Resolución 17/4 de 16 de junio de 2011. Con anterioridad, debe mencionarse la Declaración de la OIT relativa a los principios y derechos fundamentales en el trabajo y su seguimiento, adoptada por la Conferencia Internacional del Trabajo en su octogésima sexta reunión, Ginebra, 18 de junio de 1998, en la que se recuerda que "el crecimiento económico es esencial, pero no suficiente, para asegurar la equidad, el progreso social y la erradicación de la pobreza, lo que confirma la necesidad de que la OIT promueva políticas sociales sólidas, la justicia e instituciones democráticas”. Sin olvidar las Líneas Directrices de la OCDE para Empresas Multinacionales, que tienen su precedente en una Declaración de la propia OCDE de 1976 (sobre inversión internacional y empresas multinacionales) y se revisaron en 2011 justamente para adaptarse a los principios rectores del Consejo de Derechos Humanos. Con esta revisión en el ámbito de la OCDE se pretendería contribuir "a crear una sinergia y convergencia a nivel internacional respecto a los estándares existentes sobre la responsabilidad de las empresas en materia de derechos humanos. Constituyen un elemento importante en este ámbito, y contribuyen al desarrollo de una cultura de conducta empresarial responsable", como ha resaltado CANTÚ RIVERA, H.: "La OCDE y los derechos humanos: el caso de las Directrices para Empresas Multinacionales y los Puntos de Contacto Nacional”, Anuario Mexicano de Derecho Internacional, vol. XV, 2015, p. 612. ${ }^{22}$ En el caso del Consejo de Europa, sobre la base de los Principios Rectores de la ONU de 2011, el Consejo de Ministros ha adoptado la Recomendación CM/Rec(2016)3 sobre los derechos humanos y las empresas, de 2 de marzo de 2016, a su vez secundada por la Conferencia de las Organizaciones internacionales no gubernamentales (OING) del Consejo de Europa mediante la Recomendación CONF/PLE(2017)REC2, de 20 de junio de 2017. En el marco de la Unión Europea (UE), cabe mencionar iniciativas relevantes como la Plataforma Europea contra la Pobreza y la Exclusión Social (uno de los siete ejes de la Estrategia Europa 2020) o el Acta del Mercado Único de 2010, que abordan la Responsabilidad Social Corporativa. La Comunicación de la Comisión al Parlamento Europeo, al Consejo, al Comité Económico y Social Europeo y al Comité de las Regiones, "Estrategia renovada de la Unión Europea (Unión Europea) para 2011-2014 
empresas de los derechos humanos. Dichos principios, que nutren asimismo los ODS ${ }^{23}$, constituyen una guía nada desdeñable para la implementación a nivel nacional ${ }^{24}, \mathrm{y}$, aunque no sean vinculantes, sí conforman una orientación fundamental para la sensibilización, el reconocimiento de buenas prácticas y en última instancia la adopción de normas obligatorias y generadoras de deberes en la materia coherentes con lo previsto por el art. 29 de la Declaración Universal de Derechos Humanos ${ }^{25}$.

En verdad, es el art. 28 de la Declaración Universal el que dota de pleno sentido y contenido al mandato constitucional interpretativo del art. 10.2 CE. Pues, cabalmente, no nos es dado asumir unas reglas hermenéuticas que no tiendan a procurar, con responsabilidad y de buena fe, el efecto útil de los instrumentos de derechos humanos. A tal efecto, el citado art. 28 declara que "toda persona tiene derecho a que se establezca un orden social e internacional en el que los derechos y libertades proclamados en esta Declaración se hagan plenamente efectivos”. Con carácter añadido, a mi modo de ver, no es difícil establecer un claro paralelismo entre esta disposición y la cláusula de efectividad y de progreso establecida en el art. 9.2 CE ${ }^{26}$.

sobre la responsabilidad social de las empresas” Bruselas, 25.10.2011,COM(2011) 681 final, insta a los Estados miembros a desarrollar un plan de aplicación de los Principios Rectores del Consejo de Derechos Humanos de la ONU. Con el mismo objetivo de promover la Responsabilidad Social Corporativa de las empresas europeas en el exterior, la Comisión presentó en mayo de 2014 la Comunicación "Reforzar el papel del sector privado para lograr un crecimiento sostenible e inclusivo en los países en desarrollo" (COM(2014) 263 final). Y, en su Plan de Acción sobre derechos humanos y democracia 2015-2019, la UE incluye entre sus objetivos el progreso en materia de derechos humanos y empresas.

${ }^{23}$ Véase el apartado 67 de la Resolución de Naciones Unidas sobre los ODS.

${ }^{24}$ Véase el Plan de Acción Nacional de Empresas y Derechos Humanos del Gobierno de España, aprobado por Acuerdo del Consejo de Ministros de 28 de julio de 2017 (BOE n 222, de 14 de septiembre de 2017). En ese plan nacional español se justifica la base habilitante universal por referencia a la Agenda 2030 e instrumentos conexos en la materia, en estos términos: "En el marco de Naciones Unidas resulta necesario mencionar la Agenda 2030 para el Desarrollo Sostenible aprobada mediante Resolución 70/1 de la Asamblea General de Naciones Unidas (AGNU) de 25 de septiembre de 2015. Esta resolución, de carácter universal, marca los objetivos de carácter social, económico y medioambiental para lograr alcanzar 17 Objetivos de Desarrollo Sostenible (ODS) con sus 169 metas para el año 2030. Concretamente su párrafo 67 recoge una mención expresa, en el marco del fomento de un sector empresarial dinámico y eficiente, a los Principios Rectores sobre la Empresa y los Derechos Humanos, idea que se ve reforzada en la Resolución 70/224 de 22 de diciembre de 2015 sobre asociaciones mundiales de colaboración. Por otro lado, la Agenda de Acción de Addis Abeba, aprobada mediante Resolución 69/313 de la AGNU de 27 de julio de 2015, y que se incorpora en la propia Agenda 2030 como medios de implementación, también recoge en su párrafo 37 una mención a estos Principios Rectores. La Agenda 2030 invita a las empresas a alinear su estrategia corporativa de negocio con los objetivos de desarrollo para buscar el valor añadido que pueden aportar en los países en desarrollo, por lo que los ODS son un marco perfecto".

${ }^{25}$ SOLANES CORELLA, A.: "A Human Rights Perspective on the Responsibility of Transnational Corporations: Does Spain need a Plan?”, en SOLANES CORELLA, A., y GÓRRIZ ROYO, E.M. (Dirs.): Legal Challenges of the XXI Century, Valencia, Tirant lo Blanch, 2017, p. 25.

${ }^{26}$ A tenor del art. 9.2 CE: "Corresponde a los poderes públicos promover las condiciones para que la libertad y la igualdad del individuo y de los grupos en que se integra sean reales y efectivas; remover los obstáculos que impidan o dificulten su plenitud y facilitar la participación de todos los ciudadanos en la vida política, económica, cultural y social”. 
De alguna manera, la dimensión jurídica del derecho al desarrollo da pie para enfatizar la transversalidad universal y constitucional de los ODS $^{27}$, como pauta hermenéutica que permita acometer "la dualidad entre globalidad e integración desde los riesgos de la primera y las esperanzas de la segunda. Un intercambio regional a partir de la industria alimentaria para abastecer esa necesidad primaria para la población, y las mejoras en sanidad y vivienda, fortalecerían asimismo el entramado institucional y las garantías de los derechos fundamentales, mediante la emergencia de un derecho supranacional y unas instituciones de integración, así como de órganos de solución de conflictos y de protección de derechos que fuera un antídoto contra la corrupción y a favor de una justicia independiente e imparcial, que es instrumento fundamental de esa seguridad jurídica” ${ }^{28}$. En suma, como bien se ha mantenido, "en el fondo, lo que pretende el derecho al desarrollo es dar carta de naturaleza al enfoque estructural de los derechos humanos que ya figuraba en el tantas veces olvidado artículo 28 de la Declaración Universal de Derechos Humanos”29.

\section{Cuestiones sustanciales: los ODS y la efectividad de los derechos sociales}

\section{Aproximación general}

Naturalmente, la Resolución de la Asamblea General de 25 de septiembre de 2015 que aprueba la Agenda 2030 no se limita a proclamar los ODS, sino que insta a todos los actores nacionales e internacionales, públicos y privados y de la sociedad civil, a ponerlos en práctica, como verdadero plan de acción que da continuación a ese código de conducta universal que configuró la Declaración Universal de Derechos Humanos de 1948. Con semejante filosofía, bajo la rúbrica “medios de implementación”, el texto de la Declaración incluida en la Resolución de 2015 reconoce “que los parlamentos nacionales desempeñarán un papel fundamental en el cumplimiento efectivo de nuestros compromisos promulgando legislación, aprobando presupuestos y garantizando la rendición de cuentas. Los gobiernos y las instituciones públicas también colaborarán estrechamente en la implementación con las autoridades regionales y locales, las instituciones subregionales, las instituciones internacionales, la comunidad académica, las organizaciones filantrópicas, los grupos de voluntarios y otras instancias” ${ }^{30}$. Esa

\footnotetext{
${ }^{27}$ Ese carácter transversal se percibe en los distintos instrumentos de Naciones Unidas en la materia, que tuvieron una reafirmación muy importante en la Conferencia Mundial de Derechos Humanos celebrada en Viena en 1993, en cuya Declaración final se enfatizó que "la democracia, el desarrollo y el respeto de los derechos humanos y de las libertades fundamentales son conceptos interdependientes que se refuerzan mutuamente" (párrafo 8), agregándose que la Conferencia Mundial "reafirma el derecho al desarrollo, según se proclama en la Declaración sobre el derecho al desarrollo [aprobada mediante la Resolución 41/128 el 4 de diciembre de 1986], como derecho universal e inalienable y como parte integrante de los derechos humanos fundamentales” (párrafo 10).

${ }^{28}$ COLOMER VIADEL, A.: Comunidades y ciudades, Constituciones y solidaridades, Buenos Aires, Ciudad Nueva, 2015, p. 245.

${ }^{29}$ GÓMEZ ISA, F: "El derecho al desarrollo en el 25 aniversario de la Declaración sobre el derecho al desarrollo”, en PECES-BARBA MARTÍNEZ y otros (Dirs.): Historia de los Derechos Fundamentales, tomo IV, vol. VI, libro III, Madrid, Dykinson, 2013. p. 2164.

${ }^{30}$ Párrafo 45 de la Resolución sobre los ODS.
} 
interpelación a los operadores nacionales, que evoca el mandato contenido en los ya reseñados arts. 9.1, 9.2 y 53.3 de la Constitución española de 1978, se completa seguidamente con análoga invitación a las instancias internacionales ${ }^{31}$; y, ciertamente, cabe complementar "la efectividad de los derechos sociales, más allá del Estado", puesto que "las formas de efectividad de los derechos sociales no se han modificado en menor medida en el curso de la evolución de los sistemas jurídicos, una metamorfosis que acompaña de algún modo la transformación del Estado llamado social”32.

A continuación, la apuesta por la efectividad de los ODS se acentúa, en el contexto de esa declaración incluida en la Resolución de 25 de septiembre de 2016, bajo la rúbrica "un llamamiento a la acción para cambiar nuestro mundo"33, se incide en que se anuncia “una Agenda para la acción mundial durante los próximos 15 años” con formato de "carta para las personas y el planeta en el siglo XXI. Los niños y los jóvenes de ambos sexos son agentes fundamentales del cambio y encontrarán en los nuevos Objetivos una plataforma para encauzar su infinita capacidad de activismo hacia la creación de un mundo mejor" ${ }^{34}$. Adicionalmente, entroncando con la Carta de las Naciones Unidas (que comienza con la conocida frase "Nosotros los pueblos”), esa declaración de los ODS vuelve a poner en valor el papel de todos los actores, a escala nacional e internacional, proclamando que "hoy día somos 'nosotros los pueblos' quienes emprendemos el camino hacia 2030. En nuestro viaje nos acompañarán los gobiernos, así como los parlamentos, el sistema de las Naciones Unidas y otras instituciones internacionales, las autoridades locales, los pueblos indígenas, la sociedad civil, las empresas y el sector privado, la comunidad científica y académica y toda la población. Ya se han comprometido con esta Agenda millones de personas que la asumirán como propia. Es una Agenda del pueblo, por el pueblo y para el pueblo, y precisamente por ello creemos que tiene el éxito garantizado" 35 .

Esa fórmula, que rememora la célebre fórmula de la democracia como "gobierno de pueblo, por el pueblo y para el pueblo" atribuida a Abraham Lincoln en la inauguración del cementerio nacional de Gettysburg el 19 de noviembre de $1863^{36}$ y retomada incluso

\footnotetext{
${ }^{31}$ Párrafo 46: "Subrayamos el importante papel y las ventajas comparativas que tendrá el sistema de las Naciones Unidas para apoyar el logro de los Objetivos de Desarrollo Sostenible y el propio desarrollo sostenible si dispone de suficientes recursos y realiza una labor pertinente, coherente, eficiente y eficaz. Destacamos la importancia de fortalecer la titularidad y el liderazgo nacionales en los países, al tiempo que expresamos nuestro apoyo al actual proceso de diálogo del Consejo Económico y Social sobre el posicionamiento a más largo plazo del sistema de las Naciones Unidas para el desarrollo en el contexto de la presente Agenda".

${ }^{32}$ HERRERA, C.M.: Confines del Constitucionalismo, Bogotá, Universidad Externado de Colombia, 2017, p. 122.

${ }^{33}$ Párrafos 49 a 53.

${ }^{34}$ Párrafo 51.

${ }^{35}$ Párrafo 52.

${ }^{36}$ El entonces Presidente estadounidense sentenció: "the government of the people, by the people, and for the people shall not perish from the earth”. Como es sabido, la UNESCO llevó a cabo en 1949 un análisis crítico de esta proposición, manifestándose que la partícula "por el pueblo" se aproximaba más al espíritu esencialmente democrático, mientras que "del pueblo" y "para el pueblo" suscitaban ciertas reservas, dado
} 
en algunos Textos Constitucionales ${ }^{37}$, vislumbra una Agenda en la que la democracia y los derechos humanos se erigen vectores axiológicos de orden mundial ${ }^{38}$, y que se reafirma bajo la rúbrica "medios de implementación y alianza mundial” ${ }^{39}$. No sin antes recalcarse en la reiterada Declaración de los ODS que "hemos trazado el camino hacia el desarrollo sostenible, y nos corresponde a todos garantizar que el viaje llegue a buen puerto y que sus logros sean irreversibles”. Lo cual, dicho sea de paso, nos trae rápidamente a la mente la idea de progresividad y no regresión ${ }^{40}$ o, como ya apuntó

que en nombre del pueblo y para su beneficio se han pretendido justificar intervenciones supuestamente sociales que realmente escondían prácticas antidemocráticas.

${ }^{37}$ Es el supuesto emblemático de la Constitución francesa vigente de 1958, concretamente en el párrafo quinto de su artículo $1^{\circ}$ : "Su principio -de Francia- es: gobierno del pueblo, por el pueblo y para el pueblo" (“Son principe est: gouvernement du peuple, par le peuple et pour le peuple”).

38 También es cierto que la puesta en práctica de esa mundialización de la democracia no está exenta de dificultades, ligadas a factores como la influencia de los medios de comunicación y, sobre todo, el modo de financiación de las campañas electorales, las deudas asumidas por los políticos que llegan al poder, la devolución de los favores y del dinero recibido y el riesgo entonces de corrupción política y consiguientemente desvío de fondos con empobrecimiento para la población, como ha analizado COLLIER, P.: El club de la miseria. Qué falla en los países más pobres del mundo, Barcelona, Penguin Random House, $3^{\text {a }}$ ed., 2014, p. 244-245: “¿Qué más hay, aparte de los medios de comunicación? El diseño de la democracia es muy diferente dependiendo del lugar, luego es absurdo tratar de exponer un modelo de aplicación universal. No obstante, hay un aspecto de la democracia en el que las normas internacionales ayudarían a frenar los abusos: la financiación electoral. Al haberme criado en Gran Bretaña, un país cuya legislación impone a los partidos políticos unos límites muy estrictos a la hora de captar dinero y gastarlo en las campañas electorales, solía dejarme pasmado el estilo estadounidense de financiación electoral, pero es que aún no conocía el de otros países. Antes siquiera de ocuparnos del club de la miseria, el gasto electoral de las nuevas democracias es asombroso. Fijémonos, por ejemplo, en Rusia, donde una campaña electoral cuesta unas cuatro veces más que en Estados Unidos, a pesar de que la renta estadounidense es diez veces superior. En términos relativos, el coste electoral ruso es cuarenta veces mayor que el estadounidense. $\mathrm{O}$ el caso de Nigeria. Olvidémonos de las campañas electorales: la mera elección de un senador nigeriano cuesta medio millón de dólares. Con semejante nivel de gasto no es de extrañar que el país sea corrupto. Para recaudar tamaña suma, los candidatos tienen que vender sus casas, pedir préstamos y suplicar donaciones y, si salen elegidos, sólo tienen cuatro años para recuperar la inversión”. Por estas razones, los derechos humanos deben ir de la mano de la democracia, en un binomio inseparable: con tal enfoque, ha enfatizado KRIKORIÁN, M.: Derechos Humanos, políticas públicas y rol del FMI. Tensiones, errores no asumidos y replanteos, La Plata, Librería Editora Platense, 2013, p. 267: "El paradigma de los derechos humanos tiene que ser para un país la plataforma que oriente su desempeño institucional y -más específicamente- las políticas públicas que decida llevar adelante. (...) El PIDESC no exige adoptar una determinada política pública, efectivamente. Pero eso no significa sostener que la misma termine siendo neutra si la cuestión es analizada en perspectiva de derechos humanos. Un desempeño de estas características tiene efectividad si trasciende los circunstanciales gobiernos y se sustrae de los tiempos electorales. Requiere asimismo poner el acento en la igualdad y la equidad social mediante políticas inclusivas universales; esto a su vez en un marco favorable al debate y a los aportes constructivos provenientes de distintos sectores para avanzar -sin retrocesos- en dirección a crear reales oportunidades que permitan a todas las personas llevar adelante una vida digna”.

39 Particularmente, párrafo 60: "Reafirmamos nuestro decidido compromiso con la plena implementación de esta nueva Agenda. Reconocemos que será imposible lograr nuestros ambiciosos objetivos y metas sin una Alianza Mundial revitalizada y mejorada y sin unos medios de implementación que sean igualmente ambiciosos. La Alianza Mundial revitalizada facilitará una intensa participación mundial para respaldar el cumplimiento de todos los Objetivos y metas, aglutinando a los gobiernos, la sociedad civil, el sector privado, el sistema de las Naciones Unidas y otras instancias, y movilizando todos los recursos disponibles”. ${ }^{40}$ Sobre el alcance de dicho principio, en la doctrina española, véase PONCE SOLÉ, J.: El derecho y la (ir) reversibilidad limitada de los derechos sociales de los ciudadanos. Las líneas rojas constitucionales a los recortes y la sostenibilidad social, Madrid, INAP, 2013. El citado autor razona (p.78): "las regulaciones 
nuestra Jurisdicción Constitucional en su jurisprudencia inicial, la irreversibilidad de las conquistas sociales ya conseguidas (SSTC 81/1982, de 21 de diciembre, FJ 3, y 98/1983, de 15 de noviembre, FJ 4).

Este apunte no es en absoluto improcedente. Al contrario, en congruencia con el enfoque seguido en el presente trabajo, pone el punto de mira en la faceta de “constitucionalismo social” de los ODS. En puridad, un somero repaso a los diecisiete ODS (con sus ciento sesenta y nueve metas) ponen de manifiesto esa vertiente social: así, la lucha contra la pobreza como protección contra la precariedad y plenitud de ciudadanía social se recoge en los objetivos 1 (en general) y 2 (derecho a la alimentación en particular) ${ }^{41}$, así como en los objetivos 6 (derecho al agua), 7 (lucha contra la pobreza energética) y 12 (faceta de consumidores) ${ }^{42}$; la salud se consigna en el objetivo 3, mientras el acceso a la vivienda (incluida, lógicamente, la accesibilidad de las personas con discapacidad) y el derecho a la ciudad (indisociable de la lucha contra la exclusión social como trasunto de la ciudadanía política) se incluyen en los objetivos 9 y $11^{43}$; la vertiente prestacional de la educación se incorpora en el objetivo $4^{44}$; el trabajo digno y decente focaliza el objetivo $8{ }^{45}$; el índice de potenciación del género, en sentido amplio, se contiene en el objetivo $5^{46}$; los aspectos ambientales del desarrollo sostenible integran los objetivos 13, 14 y 15 ${ }^{47}$; y, completan los objetivos, algunos de carácter transversal que apuestan por la igualdad (objetivo 10), la solidaridad y la justicia (objetivo 16) ${ }^{48}$ como $^{\circ}$

que suponen regresión de prestaciones sociales deben ser justificadas por el legislador (recordemos, de nuevo, la STC 81/1982, FJ 3, exigiendo «razón suficiente» para la privación de conquistas sociales), so pena de vulnerar el art. 9.3 CE, sin que corresponda al TC tampoco inventar o crear justificaciones inexistentes".

${ }^{41}$ El objetivo 1 consiste en "poner fin a la pobreza en todas sus formas y en todo el mundo", mientras el objetivo 2 en "poner fin al hambre, lograr la seguridad alimentaria y la mejora de la nutrición y promover la agricultura sostenible".

${ }^{42}$ Los objetivos 6, 7 y 12 se refieren, respectivamente, a "garantizar la disponibilidad y la gestión sostenible del agua y el saneamiento para todos”, a "garantizar el acceso a una energía asequible, fiable, sostenible y moderna para todos” y a "garantizar modalidades de consumo y producción sostenibles”.

${ }^{43}$ El objetivo 3 persigue "garantizar una vida sana y promover el bienestar de todos a todas las edades", mientras el 9 apunta a "construir infraestructuras resilientes, promover la industrialización inclusiva y sostenible y fomentar la innovación” y el 11 a "lograr que las ciudades y los asentamientos humanos sean inclusivos, seguros, resilientes y sostenibles”.

${ }^{44}$ El objetivo 4 se centra en "garantizar una educación inclusiva y equitativa de calidad y promover oportunidades de aprendizaje permanente para todos”.

45 Objetivo 8: "Promover el crecimiento económico sostenido, inclusivo y sostenible, el empleo pleno y productivo y el trabajo decente para todos”.

${ }^{46}$ A tenor del objetivo 5, se debe "lograr la igualdad de género y empoderar a todas las mujeres y las niñas”.

${ }^{47}$ Esos objetivos ambientales radican en "adoptar medidas urgentes para combatir el cambio climático y sus efectos”, “conservar y utilizar sosteniblemente los océanos, los mares y los recursos marinos para el desarrollo sostenible” y "proteger, restablecer y promover el uso sostenible de los ecosistemas terrestres, gestionar sosteniblemente los bosques, luchar contra la desertificación, detener e invertir la degradación de las tierras y detener la pérdida de biodiversidad”.

${ }^{48}$ Con el objetivo 10 se pretende "reducir la desigualdad en los países y entre ellos” y con el 16 "promover sociedades pacíficas e inclusivas para el desarrollo sostenible, facilitar el acceso a la justicia para todos y construir a todos los niveles instituciones eficaces e inclusivas que rindan cuentas”. 
vectores de constitucionalismo global social ${ }^{49}$, para apelar a la efectividad de todos los ODS (objetivo 17) ${ }^{50}$.

\section{Enfoque concreto}

No es esta obviamente la sede para un análisis pormenorizado de cada uno de los ODS. No obstante, resulta ineludible, cuando menos, un enfoque más concreto e integrado referente a los bloques de objetivos mencionados bajo el ángulo del constitucionalismo social global multinivel que impregna el presente trabajo.

En lo atinente a los ODS relacionados con la "la erradicación de la pobreza en todas sus formas y dimensiones, incluida la pobreza extrema, [que] es el mayor desafío a que se enfrenta el mundo” (primer párrafo del Preámbulo y párrafo 2 de la declaración de la Resolución de 25 de septiembre de 2015 sobre los ODS), esto es, los objetivos 1, 2, 6, 7 y 12, tienen precedentes universales de gran relevancia: de un lado, la Conferencia Mundial de Derechos Humanos celebrada en Viena en junio de 1993 aludió en términos contundentes a la extrema pobreza y a la exclusión social como atentados a la dignidad humana $^{51}$; de otro lado, Los principios rectores sobre la extrema pobreza y los derechos humanos elaborados por la Relatora Especial Magdalena Sepúlveda y adoptados por el Consejo de Derechos Humanos de Naciones Unidas el 27 de septiembre de 2012, que ponen el énfasis en un "enfoque basado en los derechos humanos", que "proporciona un marco para erradicar la extrema pobreza a largo plazo partiendo del reconocimiento de las personas que viven en ella como titulares de derechos y agentes de cambio" 52 ; y, en tercer término, es interesante la Recomendación $n^{\circ} 202$ de la OIT relativa a los pisos nacionales de protección social (14 de junio de 2012), cuyo apartado 2 de la parte I (Objetivos, ámbito de aplicación y principios) declara que "los pisos de protección social constituyen conjuntos de garantías básicas de seguridad social definidos a nivel nacional que aseguran

\footnotetext{
49 Sobre el particular, ha advertido GUTIÉRREZ GUTIÉREZ, I.: "La constitucionalización del espacio global”, en GALERA RODRIGO, S., y ALDA FERNÁNDEZ, M. (Eds.): Construyendo el futuro: conversaciones jurídicas sobre la Globalización, Barcelona, Atelier, 2017, p. 81: "Lo relevante no es entonces la unidad de un documento constitucional o la armonía del ordenamiento, sino la posibilidad de articular garantías jurídicas eficaces de la libertad frente al poder, y también la operatividad estable de instituciones y servicios capaces de asegurar condiciones básicas de igualdad en el ejercicio de esa libertad; lo decisivo no es siquiera el Estado democrático, sino que los individuos estén en condiciones de determinar de modo eficaz el sentido de las concretas políticas públicas. Con ello se abre la posibilidad de que el Derecho constitucional, sin menoscabo de las singularidades del documento constitucional vigente en un concreto Estado, sea capaz de trascenderlo. Pongamos, para concluir, un solo ejemplo: el actual debate alemán sobre la posibilidad de limitar el número de asilados coloca en primer plano las garantías constitucionales internas, en el contexto de un uso estratégico y crítico del Derecho constitucional, europeo e internacional frente a los problemas que se plantean en el espacio global. La constitucionalización equivaldría, en definitiva, a la razón como astucia de los iuris prudentes; consistiría en una determinada perspectiva que arrojan los juristas sobre los problemas para movilizar en torno a ellos recursos argumentativos eficaces".

${ }^{50}$ El objetivo 17 se orienta a "fortalecer los medios de implementación y revitalizar la Alianza Mundial para el Desarrollo Sostenible”.

51 Apartados 14 y 25 de la Declaración final de Viena, de 25 de junio de 1993.

52 Apartados 4 y 6 del Prefacio.
} 
una protección destinada a prevenir o a aliviar la pobreza, la vulnerabilidad y la exclusión social” ${ }^{53}$.

En el ámbito regional europeo, la Carta Social, en su versión revisada de 1996, constituye el primer y único instrumento internacional que ha reconocido de manera autónoma el derecho a la protección contra la pobreza y la exclusión social ${ }^{54}$, concretamente en su art, 30, imponiendo "el acceso efectivo, en particular al empleo, a la vivienda, a la formación, a la enseñanza, a la cultura, y a la asistencia social y médica, de las personas que se encuentren o que corran el riesgo de encontrarse en una situación de exclusión social o de pobreza, así como de sus familias”; esta disposición ha sido convenientemente desarrollada por la jurisprudencia del Comité Europeo de Derechos Sociales, no pudiendo desconocerse que "el art. 30 de la Carta Social revisada no puede ser leído, comprendido o aplicado sin que se tenga siempre en mente el nexo que le une al art. 3 del Convenio que prohíbe los tratos inhumanos y degradantes y al art. 2 del propio Convenio que garantiza el derecho a la vida" 55 . Desde esta perspectiva, en el caso español es cierto que no hemos ratificado la Carta Social revisada, pero, sin perjuicio del derecho específico consagrado en ese art. 30 CSE revisada, "gracias a la jurisprudencia extraída de las decisiones del CEDS sobre las medidas adoptadas por las políticas griegas de austeridad, la Carta social europea, también en su versión de 1961, aparece dotada de un concepto normativo con el que no contaba: la protección contra la pobreza" ${ }^{\text {56 }}$. Por su lado, en el caso del CEDH, su art. 3 no ha tenido una gran virtualidad en casos de extrema pobreza, salvo en supuestos excepcionales relacionados con el drama de personas inmigrantes y refugiadas afectadas por crisis humanitarias: verbigracia, en la STEDH (Gran Sala) M.S.S. c. Bélgica y Grecia de 21 de enero de 2011, se declaró la violación del citado art. 3 CEDH por la situación de "particular gravedad” en la que se encontraba el demandante (de origen afgano) en Grecia (adonde había llegado pasando por Irán y Turquía), al no poder satisfacer “ninguna de sus necesidades más elementales: alimentarse, lavarse y alojarse" 57 .

\footnotetext{
${ }^{53}$ Véase asimismo el apartado 8 de la parte II (Pisos nacionales de protección social).

${ }^{54}$ Como bien ha argumentado GARCÍA GONZÁLEZ, G.: "La recepción de la Carta Social Europea en el ordenamiento español: aspectos jurídicos, políticos e institucionales (1978-2018)”, Revista del Ministerio de Trabajo, Migraciones y Seguridad Social, n” 137, 2018, p. 72: "los recelos que suscita la CSE en nuestro país evidencian las dudas que, con carácter general, se originan sobre el alcance y contenido de los derechos sociales, en los nuevos contextos socioeconómicos surgidos como consecuencia de los procesos de globalización y de la irrupción de las tecnologías de la información y comunicación. Sin desconocer la necesidad de adaptar el sistema de relaciones laborales a las nuevas realidades, cualquier proceso de ajuste debe pasar necesariamente por la consolidación y profundización en los derechos sociales, conquista colectiva que se ha venido presentando como instrumento indispensable de cohesión social, progreso e integración cívica. Así, en una coyuntura como la actual, con una profunda crisis de ajuste del sistema de relaciones laborales y de los valores que han sustentado el progreso social en Europa, el compromiso de España con la CSE y con los derechos sociales y sus garantías resulta, más que nunca, inexcusable”.

55 BRILLAT, R. (2009): "La Charte sociale européenne révisée: le défi des droits sociaux face à la pauvreté”, en DECAUX, E., y YOTOPOULOS-MARANGOPOULOS, A. (Dirs.) : La pauvreté, un défi pour les droits de l'homme, Paris, Pedone, 2009, p. 69.

56 STANGOS, P. (2016): "La protection des droits fondamentaux par le Comité européen des droits sociaux face aux mesures d’austérité imposées par la Grèce”, Semaine sociale Lamy. Supplément, nº 1746, p. 86. ${ }^{57}$ Párrafo 254.
} 
Es indiscutible que la lucha contra el hambre y la seguridad alimentaria representan dos vertientes de un derecho fundamental (el derecho a la alimentación) cuyo respeto se ve sometido asimismo al entrecruzamiento de las cuestiones sociales (entre las que destaca la conexión de tal derecho con la salud y la misma vida) ${ }^{58}$ y las de índole económica, por ejemplo a cuenta de una materia tan compleja como los organismos genéticamente modificados. Desde este prisma, no únicamente la salud (objetivo 3), sino también los elementos ambientales del desarrollo sostenible (objetivos 13, 14 y 15), en el panorama de la globalización económica, han sido objeto de regulación normativa y de pronunciamientos jurisprudenciales en la Unión Europea ${ }^{59}$. A este respecto, es conocido que la dignidad es el elemento axiológico medular de la Constitución y, en realidad, se erige en "paradigma universal” que, al acometer retos como el difícil equilibrio entre el progreso económico y la tutela ambiental, suscita inmediatamente la noción de "dignidad transgeneracional” ${ }^{60}$. Por lo demás, las cuestiones de medio ambiente y de salud también han sido acometidas por la jurisprudencia del TEDH en clave de obligaciones positivas, de tal manera que "un riesgo o amenaza para el medio ambiente y la salud de las personas, derivada de una actividad peligrosa son suficientes para exigir al Estado su intervención. Esto quiere decir que su responsabilidad está comprometida desde ese primer momento. Así, el Estado debe actuar para evitar que las actividades peligrosas puedan afectar, especialmente, a la vida (art. $2 \mathrm{CEDH}$ ) o el bienestar de las personas (art. $8 \mathrm{CEDH}$ ) desde el estadio inicial en el que presentan tales riesgos o amenazas"61.

Por descontado, la lucha contra el hambre lleva implícita la lucha contra la sed y, en este caso, cobra una especial relevancia el derecho al agua, cuyo alcance y contenido ha sido derivado en sus perfiles más exigentes de los arts. 11 y 12 del Pacto Internacional de Derechos Económicos, Sociales y Culturales, especialmente a través de la Observación General n ${ }^{\circ} 15$ de 2003 del Comité DESC de la ONU ${ }^{62}$. Con semejante base habilitante,

58 COSTANZO, P.: “Biotecnologie, militanze e diritti fondamentali”, en COSTANZO, P. (Coord.): Organismi geneticamente modificati. Una prospettiva giuridica, Genova, Genova University Press, 2016, p. 2.

${ }^{59}$ Véase, entre otras, SSTJUE de 2 de octubre de 2014 (Comisión Europea/Polonia, asunto C-478/13), de 6 de septiembre de 2011 (Karl Heinz Bablok y otros/Freistaat Bayern, asunto C-442/09), y de 17 de febrero de 2009 (Commune de Sausheim/Pierre Azelvandre, asunto C-552/07), todas ellas sobre la Directiva 2001/18/CE del Parlamento Europeo y del Consejo, de 12 de marzo de 2001, sobre la liberación intencional en el medio ambiente de organismos modificados genéticamente, y alimentos que contengan ingredientes producidos a partir de dichos organismos [véase asimismo el Reglamento (CE) $\mathrm{n}^{0}$ 1829/2003 del Parlamento Europeo y del Consejo, de 22 de septiembre de 2003, sobre alimentos y piensos genéticamente modificados].

${ }^{60}$ CECCHERINI, E.: “Dignità, tutela ambientale, ciclo dei rifiuti”, en COSTANZO, P. (Coord.): Aspetti e problemi del ciclo e del riciclo dei rifiuti, Genova, Genova University Press, 2018, pp. 297 y 308 . Véase asimismo, con anterioridad, las diversas contribuciones incluidas en BIFULCO, R., y D'ALOIA, A. (Coords.): Un diritto per il futuro. Teorie e modelli dello sviluppo sostenibile e della responsabilità intergenerazionale, Napoli, Jovene, 2008.

${ }^{61}$ SÁNCHEZ PATRÓN, J.M. "Las actividades peligrosas para el medio ambiente y la salud humana en la jurisprudencia del Tribunal Europeo de Derechos Humanos”, en SÁNCHEZ PATRÓN, J.M. (Coord.): Bioderecho Internacional y Europeo, Valencia, Tirant lo Blanch, 2014, p. 138.

62 En el pár. 2 de dicha Observación General no 15/2003 se define el derecho al agua como "el derecho de todos a disponer de agua suficiente, salubre, aceptable, accesible y asequible para el uso personal y 
se ha esgrimido que “todos los Estados tienen la obligación positiva de garantizar el acceso a la cantidad esencial mínima de agua que sea suficiente y apta para el uso personal y doméstico, y para prevenir las enfermedades"63.

En el caso de España, además, un parámetro internacional nada desdeñable viene representado por la Carta Social Europea en su irrefutable caracterización como “Constitución Social de Europa” ${ }^{64}$, de cuyo marco se deriva igualmente la exigibilidad jurídica del derecho al agua (en particular, el derecho a la vivienda como parte de la protección jurídica, económica y social de la familia del art. 16); lo cual, lógicamente, debería venir reforzado por la todavía pendiente ratificación por parte de España de la Carta revisada de 1996 (la cual contiene disposiciones más incisivas, concretamente el derecho a la protección contra la pobreza y la exclusión social del art. 30 y el autónomo derecho a la vivienda del art. 31) ${ }^{65}$, sin desmerecer las disposiciones nacionales (estatales o autonómicas) ${ }^{66}$ en la materia en las coordenadas de una amplia "protección multi-nivel” (enfoque más global, con la toma en consideración de los diferentes focos y ramas de poder) de los derechos fundamentales respaldada asimismo por una más restringida "protección multi-jurisdiccional” ${ }^{67}$. A esta última se acercaría más bien el procedimiento

doméstico. Un abastecimiento adecuado de agua salubre es necesario para evitar la muerte por deshidratación, para reducir el riesgo de las enfermedades relacionadas con el agua y para satisfacer las necesidades de consumo y cocina y las necesidades de higiene personal y doméstica”.

63 SAURA ESTAPÀ, J.: "El derecho humano al agua potable y al saneamiento en perspectiva jurídica internacional”, en PECES-BARBA MARTÍNEZ y otros (Dirs.): Historia de los Derechos Fundamentales, op.cit., p. 2022.

${ }^{64}$ SALCEDO BELTRÁN, C.: "Derechos sociales y su garantía: la ineludible aprehensión, disposición e implementación de la Carta Social Europea (Constitución Social de Europa)”, Revista de Derecho Social, $n^{\circ}$ 83, 2018, p. 73: “es más que patente la relevancia que tiene la jurisprudencia del CEDS como parámetro de protección más elevado y su legítima y necesaria implementación por los órganos jurisdiccionales nacionales".

${ }^{65}$ Según el art. 31 de la Carta Social revisada (derecho a la vivienda): "Para garantizar el ejercicio efectivo del derecho a la vivienda, las Partes se comprometen a adoptar medidas destinadas: 1 . a favorecer el acceso a la vivienda de un nivel suficiente; 2 . a prevenir y paliar la situación de carencia de hogar con vistas a eliminar progresivamente dicha situación; 3. a hacer asequible el precio de las viviendas a las personas que no dispongan de recursos suficientes”.

${ }^{66}$ En el ámbito regional, véase a título de ejemplo el art. 17 del Estatuto de Autonomía de la Comunitat Valenciana (tras la reforma introducida mediante la Ley Orgánica 1/2006, de 10 de abril): “1. Se garantiza el derecho de los valencianos y valencianas a disponer del abastecimiento suficiente de agua de calidad. Igualmente, se reconoce el derecho de redistribución de los sobrantes de aguas de cuencas excedentarias atendiendo a criterios de sostenibilidad de acuerdo con la Constitución y la legislación estatal. Los ciudadanos y ciudadanas valencianos tienen derecho a gozar de una cantidad de agua de calidad, suficiente y segura, para atender a sus necesidades de consumo humano y para poder desarrollar sus actividades económicas y sociales de acuerdo con la Ley. 2. Toda persona tiene derecho a gozar de una vida y un medio ambiente seguro, sano y ecológicamente equilibrado. La Generalitat protegerá el medio ambiente, la diversidad biológica, los procesos ecológicos y otras áreas de especial importancia ecológica”.

67 ROSOUX, G.: “Au coeur de la protection «multi-niveaux» et du dialogo juridictionnel : la «dématérialisation» des droits fondamentaux comme clé de lectura du raisonnement actual dans le domaine des droits fondamentaux”, Fundamentos, no 9 (“La era de los derechos”), 2016, especialmente, pp. 76 a 82. Dicha autora, en el caso del CEDH, residencia la protección multi-nivel en el art. 53, desplazando la protección multi-jurisdiccional al art. 35 (con la exigencia del agotamiento de los recursos internos) del texto convencional europeo. 
de reclamaciones colectivas ante el CEDS (no asumido aún por parte de España) ${ }^{68}$, que pese a todo presenta una dimensión preventiva de primera magnitud, al margen del preceptivo mecanismo de informes establecido mediante la Carta Social originaria de $1961^{69}$.

La mencionada referencia al agua en el seno de la vivienda nos acerca a los objetivos habitacionales de la Agenda 2030 (ODS 9 y 11). En lo que concierne a la vivienda, la Agenda 2030 apela al desarrollo de acciones más concretas, las cuales han venido en primer término de la mano de la Conferencia de Naciones Unidas sobre vivienda y desarrollo urbano sostenible (conocida como Hábitat III), celebrada en Quito del 17 al 20 de octubre de $2016^{70}$ y tendente a reforzar la "Nueva Agenda Urbana"71. Desde este punto de vista, parece inaudito que todavía estemos persiguiendo hacer realidad una necesidad que es un mínimo vital (la vivienda, igual que la alimentación o

\footnotetext{
${ }^{68}$ En fechas recientes, el Gobierno español acordó, en su reunión del Consejo de Ministros de 1 de febrero de 2019, la remisión de la Carta revisada a las Cortes Generales para su ratificación, descartando la asunción del citado Protocolo de 1995; por lo que, lamentablemente, la propuesta seguía teniendo dicha asignatura pendiente, a menos que se aprovechara la ratificación de la Carta revisada para, en virtud de su art. D.2, aceptar al mismo tiempo el mecanismo judicial de reclamaciones. Ello en la línea propugnada por el llamado “proceso de Turín” lanzado por el Consejo de Europa en octubre de 2014 [véase: https://www.coe.int/en/web/european-social-charter/turin-process]. Esa posible ratificación de la CSE revisada (y, con ella, la aceptación del procedimiento de reclamaciones) ha quedado frustrada con la disolución anticipada de las Cortes Generales y la convocatoria de las elecciones generales del 28 de abril de 2019.

69 De nuevo, como acertada y detalladamente ha analizado GARCÍA GONZÁLEZ, G.: "La recepción de la Carta Social Europea en el ordenamiento español: aspectos jurídicos, políticos e institucionales (19782018)”, op. cit., p. 56: "La inexistencia de argumentos jurídicos que impidan la ratificación de la CSE revisada por España, debe llevar a pensar que la ausencia de ratificación solo puede imputarse a una inexistente voluntad política al respecto. Lo mismo puede predicarse respecto a la firma y ratificación del Protocolo de reclamaciones colectivas de 199556. Parece que criterios de oportunidad política invitan a los poderes públicos a no ratificar la CSE revisada y el Protocolo de 1995 hasta este momento; criterios de oportunidad que en otro contexto histórico aconsejaron la rápida ratificación de España de la CSE originaria, tan solo cinco meses después de su adhesión al Consejo de Europa, como muestra evidente del proceso de democratización que se estaba viviendo en España y del compromiso que se mantenía con el reconocimiento y la garantía de los derechos sociales. Cuatro décadas después, parece que la voluntad política es otra”.

${ }^{70}$ Dichas Cumbres sobre vivienda se celebran cada 20 años, habiendo tenido lugar Hábitat I en 1976 (del 31 de mayo al 11 de junio en Vancouver) y Hábitat II en 1996 (del 3 al 14 de junio en Estambul).

${ }^{71}$ En la Nueva Agenda Urbana, los líderes mundiales se comprometieron a: Proporcionar servicios básicos para toda la ciudadanía (acceso a la vivienda, agua potable y saneamiento, alimentos nutritivos, atención de la salud y planificación familiar, educación, cultura y acceso a las tecnologías de comunicación); garantizar que toda la ciudadanía tenga acceso a la igualdad de oportunidades y libre de discriminación respecto a los beneficios que sus ciudades ofrecen; promover medidas en apoyo de ciudades más limpias; fortalecer la resiliencia en las ciudades para reducir el riesgo y el impacto de los desastres; tomar medidas para hacer frente al cambio climático mediante la reducción de sus emisiones de gases de efecto invernadero; respetar plenamente los derechos de los refugiados, los migrantes y los desplazados internos, independientemente de su situación migratoria, teniendo en cuenta la contribución positiva de ellos a la vida urbana; mejorar la conectividad y apoyar iniciativas innovadoras y ecológicas, y promover espacios públicos seguros, accesibles y ecológicos (con aumento de los espacios públicos como aceras, carriles para bicicletas, jardines, plazas y parques). Para la implementación de dichos objetivos, se apela, entre otras medidas, a nuevas reglas y regulaciones urbanas, mejorar la planificación, el diseño urbano y las finanzas municipales.
} 
el vestido) asociado a la condición humana e inherente a la dignidad de la persona ${ }^{72}$. Pues es indudable que la cobertura y satisfacción de dichas necesidades constituye una condición previa para el goce del conjunto de derechos humanos y que debe permitir "el libre y pleno desarrollo de la personalidad al que se refiere el art. 29 de la Declaración Universal"73. Sin embargo, la realidad social de nuestro mundo actual nos muestra que "miles de millones de nuestros ciudadanos siguen viviendo en la pobreza y privados de una vida digna"74; incluso en países considerados “desarrollados”, en donde la crisis económica y financiera iniciada en 2008 comportó “subcrisis” de vivienda y de hipotecas, junto con el drama de los desahucios y los desalojos de personas en situación precaria (abocadas al "sinhogarismo") ${ }^{75}$. En consecuencia, los ODS se alzan como una sólida fuente inspiradora tendente a dotar de vigencia al reconocimiento constitucional del derecho a la vivienda ${ }^{76}$.

Finalmente, otro bloque de ODS es susceptible de una consideración integrada de la garantía de una educación inclusiva y equitativa de calidad ${ }^{77}$ mediante la que se promuevan oportunidades de aprendizaje para todos (objetivo 4) y, como prolongación de ello, de la garantía del trabajo decente para todos (objetivo 8$)^{78}$; ambos objetivos se hallan a su vez imbricados con la igualdad de género (objetivo 5). Desde luego, para llevar a cabo los ODS en este terreno, no debe perderse de vista la crítica según la cual el índice de potenciación del género ha estado más centrado en medir el empoderamiento de la

\footnotetext{
72 Algunos autores han aludido a un mínimo social garantizado compuesto por cinco necesidades fundamentales (alimentación, vestido, vivienda, salud y cultura), constituyendo las cinco primeras el "mínimo vital” y las dos últimas el "mínimo humano": en tal sentido, MARC, A.: Le fédéralisme face au futur, Nice, Presses d'Europe, 1990, pp. 26-27.

73 MARIE, J.B.: "Préface", en el la obra colectiva Le noyau intangible des droits de l'homme, Fribourg, Éditions Universitaires, 1991, pp. 12-13.

${ }^{74}$ Apartado 14 de la “Introducción” incluida en la Declaración de la Agenda 2030.

${ }^{75}$ Véase esta problemática, en clave internacional y comparada, en ESCOBAR ROCA, G.: XVI Informe sobre derechos humanos 2018 (Monográfico sobre "Vivienda") de la Federación Iberoamericana de Omdudsman (FIO), Madrid, Editorial Trama, 2018, 541 páginas.

${ }^{76}$ Con dicha filosofía, léase JIMENA QUESADA, L.: "El derecho constitucional a la vivienda digna en el marco de los objetivos de desarrollo sostenible (ODS)”, en PATÓN GARCÍA, G. (Dir.): Aspectos financieros y tributarios del patrimonio inmobiliario, Madrid, Wolters Kluwer, 2018, pp. 47-78.

77 Tras poner el énfasis en la función social del servicio público de la educación, han comentado REYES SÁNCHEZ, G.M., DÍAZ FLÓREZ, G.A., DUEÑAS SUATERNA, J.A., y BERNAL ACOSTA, A. “¿Educación de calidad o calidad de la educación? Uno de los Objetivos de Desarrollo Sostenible y el camino para el desarrollo humano?, Revista de la Universidad de la Salle, n 71, 2016, p. 258-259: "Una educación de calidad debe contribuir a formar un ser humano de calidad, para una sociedad de calidad, en la cual sus miembros gocen de una vida de calidad. Esto implica una educación que al plegarse a la calidad, como cualidad, se aviene al propósito de la búsqueda de un mejor estatus de vida para aquellos a quienes cobija”.

${ }^{78}$ Esta interrelación la ha subrayado SOTELO, I.: “Globalización: concepto y consecuencias”, en VV.AA.: La globalización más allá de la empresa, Castellón, Universitat Jaume I, 2003, p. 101: “Si las mayores víctimas de la globalización son obreros no cualificados, cuya demanda decrece con el aumento del comercio internacional -las ventajas comparativas de los países desarrollados radican en la realidad cultural y tecnológica de los recursos humanos- la respuesta no es otra que ofrecen una mejor educación para el conjunto de la población. (...) El factor decisivo para aprovechar las ventajas y reducir los inconvenientes de la población es la educación. Cabe mostrar empíricamente la relación directa que existe entre ingresos de una persona y nivel educativo. Sólo una población educada puede responder a los retos que conlleva la globalización”.
} 
mujer ${ }^{79}$ que su bienestar real ${ }^{80}$. Con tal espíritu, se ha argumentado certeramente que "la realidad exige una visión más transversal de la igualdad, no sólo en el sentido de ver cómo las políticas de igualdad deben impregnar todas las políticas y todas las esferas de la sociedad, sino también en observar cómo de modo transversal u horizontal concurren varias causas de discriminación en una persona o colectivo. Incluso, ello puede exigir, entre otras cosas, una coordinación” entre quienes luchan contra la discriminación por razón de raza, de sexo, de discapacidad, etc., de tal suerte que "la existencia de leyes antidiscriminatorias únicas o transversales, en el sentido de contemplar en un único texto varias causas de discriminación, no perjudican a la tradicional lucha” y “ayudan a resolver los problemas de la doble o múltiple discriminación” ${ }^{81}$. Verdaderamente, si abordamos de modo interconectado esos tres objetivos (4, 5 y 8), cabe concluir que todos ellos entroncan con el fracaso de la acción cultural (e incluso multicultural) ${ }^{82} \mathrm{y}$, como resultado, con una violación de los derechos culturales que a su vez conduce a una especie de “empobrecimiento sostenible" alimentado por la criticada multiplicación de discriminaciones ${ }^{83}$.

\section{Ilustraciones de implementación en España}

Si el corazón de los ODS se relaciona con el constitucionalismo social (en la estela de los previos Objetivos del Milenio, que ya avanzó "una agenda social emergente de la globalización” ${ }^{84}$ ), y este en el caso español tiene su reflejo más fiel en los principios

\footnotetext{
${ }^{79}$ Básicamente, la presencia y el poder de participación y decisión de la mujer en el ámbito político, en el terreno económico y en el mundo laboral (contra la brecha salarial).

${ }^{80}$ Véase ABRIL STOFFELS, R.: "Mujer y desarrollo en el siglo XXI: resultados de un largo y difícil proceso”, en SANZ CABALLERO, S. (Ed.): Colectivos vulnerables y derechos humanos. Perspectiva internacional, Valencia, Tirant lo Blanch, 2010, p. 220.

${ }^{81}$ SERRA CRISTÓBAL, R.: "La mujer como especial objeto de múltiples discriminacione4s. La mujer multidiscriminada”, en SERRA CRISTÓBAL, R. (Coord.): La discriminación múltiple en los ordenamientos jurídicos español y europeo, Valencia, Tirant lo Blanch, 2013, p. 42.

82 RUIZ VIEYTEZ, E.J.: "Introducción: sobre multiculturalidad, derechos y acomodos”, en RUIZ VIEYTEZ, E.J., y URRUTIA ASUA, G. (Eds.). Derechos humanos en contextos multiculturales. ¿Acomodo de derechos o derechos de acomodo?, Bilbao, Instituto de Derechos Humanos Pedro Arrupe/Diputación Foral de Gipuzkoa, 2010, p. 21: La diversidad cultural o identitaria implica el escenario plural “en el que se activan más dinámicas sociales o incluso económicas y en el cual los distintos miembros de la comunidad política pueden explotar adecuadamente sus potencialidades. La cuestión es cómo proceder a una relectura eficaz de los derechos humanos como discurso universal a la vez que flexible en su aplicación. La idea de acomodo, entendida en sus términos más amplios, se presenta aquí como clave de una relectura de los derechos construida a partir de una idea inclusiva y plural de la ciudadanía”, como una “profundización pluralizadora de la democracia” que ofrezca pautas “para quienes tienen la responsabilidad directa de diseñar políticas públicas sobre realidades crecientemente multiculturales”.

${ }^{83}$ MEYER-BISCH, P.: "Les violations des droits culturels, facteur d'appauvrissement durable: pour une observation des pauvretés culturelles”, en DECAUX, E., y YOTOPOULOS-MARANGOPOULOS, A. (Dirs.) : La pauvreté, un défi pour les droits de l’homme, op.cit., p. 81 y p. 195.

${ }^{84}$ SANAHUJA, J.A.: "De los Objetivos del Milenio al desarrollo sostenible: Naciones Unidas y las metas globales post-2015”, Anuario Ciepaz, 2014-2015. Focos de tensión, cambio geopolítico y agenda global, 2014, p. 51.
} 
rectores de la política social y económica del Capítulo tercero del Título I ${ }^{85}$, la cláusula del art. 53.3 CE, a tenor del cual esos principios “informarán la legislación positiva, la práctica judicial y la actuación de los poderes públicos”, adquiere pleno significado para dotar de vigencia en España a los ODS. Es más, ese constitucionalismo social asume una relevancia especial multinivel, no únicamente en el terreno estatal ${ }^{86}$, sino asimismo por referencia al ámbito regional, dado que las competencias autonómicas se desenvuelven en su mayor parte en clave de políticas públicas (normativas, ejecutivas y administrativas) orientadas a la defensa de los derechos sociales. Por su parte, las entidades locales ocupan un lugar fundamental, en términos de diplomacia subnacional, en el espacio global para la consecución de los ODS en materia social y ambiental ${ }^{87}$, dado que "los ODS demandan una organización del conocimiento con nuevas fórmulas políticas transfronterizas puesto

\footnotetext{
${ }^{85}$ Sobre el alcance de dicho bloque constitucional ha opinado OLIVÁN, F.: Para una lectura radical de la Constitución de 1978, Madrid, Escolar y Mayo, 2016, p. 122: "El Estado social del siglo XXI no se caracteriza por la mera acumulación de nuevos derechos, los denominados derechos sociales o prestacionales, sino más bien por su transformación. La tesis que aquí se defiende es justamente esta: los derechos sociales modernos no son sino los propios derechos fundamentales sometidos a la exigencia social. (...) Con ello se alcanza definitivamente la esfera de la calidad de la vida”.

${ }^{86}$ En el ámbito estatal, los ODS han sido asumidos de modo transversal para la acción gubernamental y ejecutiva: lo ilustra la Orden PCI/86/2019, de 31 de enero, por la que se publica el Acuerdo del Consejo de Ministros de 7 de diciembre de 2018, por el que se aprueba el Plan de Contratación Pública Ecológica de la Administración General del Estado, sus organismos autónomos y las entidades gestoras de la Seguridad Social (2018-2025). En dicha Orden se dice que "en un entorno mundial que tiene como objetivo fundamental crecer de forma sostenible, se debe tener en cuenta que la Asamblea General de las Naciones Unidas ha aprobado, mediante Resolución de 25 de septiembre de 2015, el documento Transformar nuestro mundo: la Agenda 2030 para el Desarrollo Sostenible, en el que se reconoce que es este uno de los mayores desafíos del futuro inmediato. La Agenda plantea 17 Objetivos de Desarrollo Sostenible con 169 metas de carácter integrado e indivisible que abarcan las esferas económica, social y ambiental. La nueva estrategia regirá los programas de desarrollo mundiales durante los próximos quince años. Al adoptarla, los Estados se comprometieron a movilizar los medios necesarios para su puesta en práctica, mediante una responsabilidad común y universal, los Estados tienen soberanía plena sobre su riqueza, recursos y actividad económica, y cada uno fijará sus propias metas nacionales, apegándose a los Objetivos de Desarrollo Sostenible”. Y, por supuesto, para el lógico cumplimiento de los ODS, estos han determinado la confección del organigrama gubernamental: sobre el particular, véase el Real Decreto 1271/2018, de 11 de octubre, por el que se desarrolla la estructura orgánica básica del Ministerio de Asuntos Exteriores, Unión Europea y Cooperación y por el que se modifica el Real Decreto 595/2018, de 22 de junio, por el que se establece la estructura orgánica básica de los departamentos ministeriales. En concreto, en el art. 14 se establecen las competencias de la Dirección General de Políticas de Desarrollo Sostenible para impulsar la implementación de los ODS de la Agenda 2030.

${ }^{87}$ Así lo expresa GALERA RODRIGO, S.: "Una aproximación positiva a la globalización jurídica”, en GALERA RODRIGO, S., y ALDA FERNÁNDEZ, M. (Eds.): Construyendo el futuro: conversaciones jurídicas sobre la Globalización, op.cit., p. 45: “Aun cuando en las aulas de las facultades de Derecho seguimos afirmando el monopolio estatal en la acción internacional, desde hace décadas este modelo postwestfaliano conoce más que matices. Dese los años ' 80 se viene analizando el fenómeno de la paradiplomacia, que atiende a las relaciones internacionales que los entes subestatales efectivamente desarrollan. Probablemente por su significación política, las relaciones internacionales de las entidades regionales han resultado preeminentes en esta área de estudio, no faltando los pronunciamientos jurisprudenciales sobre el particular. Sin embargo, en paralelo y de forma más silenciosa, las entidades locales han desarrollado también una intensa actividad internacional, city diplomacy, si bien con una connotación menos unilateral y más asociativa que la de los gobiernos regionales. Primero las cuestiones ambientales, y más recientemente las climáticas, han potenciado de forma importante esta actividad”.
} 
que constituyen un reto de gobernabilidad mundial sin precedentes históricos. Los ODS requieren desarrollar nuevas sinergias multidimensionales de carácter glocal”88.

Consecuentemente, el presente apartado ilustrará justamente las principales acciones de índole normativa, ejecutiva y administrativa adoptadas por algunas Comunidades Autónomas para la implementación de los ODS. Desde esta óptica, el inciso final del art. 53.3 CE (los principios rectores de la política social y económica "sólo podrán ser alegados ante la Jurisdicción ordinaria de acuerdo con lo que dispongan las leyes que los desarrollen”), lejos de percibirse como una cláusula secundaria o relegada ${ }^{89}$, se verá tanto más dinamizada cuanto mayores y mejores sean esas acciones regionales. Dicho de otro modo, la intermediación de los entes regionales (y locales) desarrollando esos principios (y, por ende, los ODS) propiciará la normal alegación de ellos ante los órganos jurisdiccionales ordinarios y eventualmente ante la Jurisdicción Constitucional en los excepcionales supuestos de amparo constitucional (que utilicen por vía de conexión los arts. 14 a $30 \mathrm{CE}$ ) o en los procesos de constitucionalidad o competenciales que involucren a las Comunidades Autónomas (o a las Entidades Locales).

Lo recién expresado, por supuesto, sin perjuicio de las resoluciones de la Jurisdicción Ordinaria o de la Jurisdicción Constitucional que citen expresamente, a efectos hermenéuticos, la Resolución de 2015 sobre la Agenda 2030, y que son hasta el momento bastante aisladas. En particular, entre las primeras, cabe mencionar la Sentencia $n^{\circ} 2660$ de 27 de abril de 2017 (recurso n ${ }^{\circ}$ 7098/2016) de la Sala de lo Social del Tribunal Superior de Justicia de Cataluña (en materia de indemnización a trabajador tras insolvencia de la empresa empleadora), a la que se incorpora un voto particular (suscrito por varias magistradas y varios magistrados de dicha Sala) en el que se argumenta que “encontrándonos ante supuesto de contratos a tiempo parcial, las propias instituciones internacionales vienen determinando su carácter precario, siendo así que la Agenda 2030 para el Desarrollo Sostenible de las Naciones Unidas, entiende como 'empleo precario' aquel que presenta 1) una retribución muy baja, 2) muy pocas horas de trabajo sin poder optar a más, o 3) poca seguridad del puesto de trabajo”. En cuanto a las resoluciones de nuestra Jurisdicción Constitucional, la referencia viene dada por la STC 15/2018, de 22 de febrero de 2018 (en el marco de un conflicto de competencias entre Cataluña y el Estado), a propósito de normativa estatal relacionada con las cuestiones ambientales

\footnotetext{
${ }^{88}$ COLLADO RUANO, J.: "Epistemología del Sur: una visión descolonial a los Objetivos de Desarrollo Sostenible”, Sankofa. Revista de História da África e de Estudos da Diáspora Africana, № XVII, 2016, p. 138.

${ }^{89}$ Suscribo así la crítica constructiva lanzada por DE LA QUADRA-SALCEDO FERNÁNDEZ DEL CASTILLO, T.: "Estado del bienestar y derechos sociales en un mundo transnacional", en PENDÁS, B. (Dir.): España Constitucional (1978-2018). Trayectorias y perspectivas, Madrid, Centro de Estudios Políticos y Constitucionales, 2018, Tomo I, p. 737: respecto a ese Capítulo tercero del Título I "puede decirse sin exageración alguna que es el decisivo para caracterizar nuestra Constitución y en general todas las Constituciones europeas de postguerra. Sin embargo, la propia denominación de la rúbrica como principios rectores o las previsiones del art. 53.3 CE sobre que solo podrán ser alegados ante la jurisdicción ordinaria de acuerdo con lo que dispongan las leyes que los desarrollen, ha llevado a algunos a desorientarse sobre el valor crucial que tiene dicho capítulo y los principios y derechos que contiene”.
} 
acometidas en el marco de los ODS ${ }^{90}$; por lo demás, en las SSTC 31/2018, de 10 de abril, 53/2018, de 24 de mayo, 66/2018, de 21 de junio, y 74/2018, de 5 de julio, se incorpora análogo voto particular en el que se trae a colación "el objetivo 4 de la agenda 2030 para el desarrollo sostenible de Naciones Unidas, dedicado a garantizar una educación inclusiva, equitativa y de calidad y promover oportunidades de aprendizaje durante toda la vida para todos”.

Efectuemos, pues, un breve repaso a la legislación autonómica que se hace eco explícitamente de los ODS, ya sea más modestamente en sus declaraciones preambulares, ya sea más incisivamente en sus textos articulados, o en ambos a la vez.

En cuanto al primer enfoque, es pionera la Ley Foral 15/2016, de 11 de noviembre, por la que se regulan los derechos a la Inclusión Social y a la Renta Garantizada, cuya Exposición de Motivos engarza la competencia autonómica en la materia con los ODS tendentes a la erradicación de la pobreza ${ }^{91}$, con mención explícita de la Agenda 2030 y del art. 25 de la Declaración Universal de $1948^{92}$. Por su lado, la Exposición de Motivos de la Ley 4/2018, de 8 de octubre, para una Sociedad Libre de Violencia de Género en Castilla-La Mancha, engarza con el ODS referente a la igualdad de género y

\footnotetext{
${ }^{90}$ Se razona así en la STC 15/2018, FJ 3 in fine: “En definitiva, a raíz del protocolo de Kioto, del Derecho de la Unión Europea, y de los instrumentos que se han articulado en España en cumplimiento de los mismos para luchar contra el cambio climático, se está promoviendo una nueva realidad económica en la que los derechos de emisiones y los créditos de carbono transmisibles son instrumentos de mercado que tienen por objeto impulsar la reducción de gases efecto invernadero de una forma eficaz y económicamente eficiente, tal y como se reconoce en el séptimo programa general de acción de la Unión en materia de medio ambiente, en donde la lucha contra el cambio climático se establece entre sus objetivos prioritarios [art. 2 b) de la Decisión 1386/2013/UE del Parlamento y del Consejo de 20 de noviembre de 2013, relativa al programa general de acción de la Unión en materia de medio ambiente hasta 2020 «vivir bien, respetando los límites de nuestro planeta»), y se ha puesto de relieve en la Resolución aprobada por la Asamblea General de Naciones Unidas el 25 de Septiembre de 2015, «Transformar nuestro mundo: la Agenda 2030 para el Desarrollo Sostenible», en donde se establece como objetivo de desarrollo sostenible núm. 13 «adoptar medidas urgentes para combatir el cambio climático y sus efectos»”.

${ }^{91}$ Sobre la influencia de los estándares internacionales en la elaboración de la normativa nacional en dicho ámbito, léase CARMONA CUENCA, E.: "El derecho a un mínimo vital y el derecho a la renta básica", Anuario de Derechos Humanos, no 13, 2017, pp. 199-209.

${ }^{92}$ En la Exposición de Motivos de la Ley navarra cabe leer: "El artículo 25.1 de la Declaración Universal de Derechos Humanos y los diversos instrumentos de desarrollo de la misma consagran, entre otros derechos económicos, sociales y culturales, el derecho de toda persona a un nivel de vida adecuado que le asegure, así como a su familia, la salud y el bienestar, y en especial la alimentación, el vestido, la vivienda, la asistencia médica y los servicios sociales necesarios; tiene asimismo derecho a los seguros en caso de desempleo, enfermedad, invalidez, viudez, vejez u otros casos de pérdida de sus medios de subsistencia por circunstancias independientes de su voluntad. Este derecho a un nivel de vida adecuado es el fundamento de la protección social en casos de vulnerabilidad o exclusión social o en riesgo de estarlo, y en consecuencia comporta la responsabilidad de los poderes públicos ante las personas que por circunstancias diversas se encuentran en tales situaciones. (...) Cabe resaltar igualmente que mediante la Resolución 70/1, de 25 de septiembre de 2015, de la Asamblea General de Naciones Unidas, por la que se aprueba la Agenda 2030 para el Desarrollo Sostenible, se fija, entre otros objetivos y metas, el de reducir la desigualdad dentro de los países y entre ellos, y en particular que desde 2015 a 2030 se debe lograr progresivamente y mantener el crecimiento de los ingresos del $40 \%$ más pobre de la población a una tasa superior a la media nacional de cada país y que se debe potenciar y promover la inclusión social, económica y política de todas las personas, independientemente de su edad, sexo, discapacidad, raza, etnia, origen, religión o situación económica u otra condición”.
} 
empoderamiento de las mujeres y las niñas ${ }^{93} \mathrm{y}$, tras una profusa referencia a los estándares universales y europeos en la materia, declara que "la adhesión de España a tales instrumentos legales internacionales en defensa de los derechos humanos refuerza, en consecuencia, la obligación de las Administraciones Públicas de responder con la diligencia debida en el ámbito de sus competencias, cumpliendo asimismo el mandato emanado del art. 9.2 de la Constitución Española de garantizar la igualdad real y efectiva, para lo que deberán remover todos los obstáculos que la impidan o dificulten”. De la misma fecha es la Ley 8/2018, de 8 de octubre, de medidas frente al cambio climático y para la transición hacia un nuevo modelo energético en Andalucía, en cuyo texto expositivo se relacionan los compromisos ambientales asumidos en el seno de la UE en conexión con los de la Agenda 2030 ${ }^{94}$. En fin, la Exposición de Motivos de la Ley 11 /2018, de 21 de diciembre, de ordenación territorial y urbanística sostenible de Extremadura, incide en los ODS relativos a la vivienda y al derecho a la ciudad ${ }^{95}$.

Por otra parte, la Comunitat Valenciana ha sido especialmente dinámica en los dos últimos años (2017 y 2018) en la toma en consideración de la Agenda 2030 para la redacción de normas e implementación de políticas públicas. Así, una primera tímida referencia vino de la mano del Preámbulo de la Ley 1/2017, de 1 de febrero, por la que se crea la Agencia Valenciana de la Innovación, cuyo principal cometido se cifra en “ciencia, tecnología e innovación”, que "ejercen un papel crucial para el cumplimiento de los objetivos de desarrollo sostenible de la Agenda 2030 de las Naciones Unidas”. Unos meses más tarde se adoptó la Ley valenciana 15/2017, de 10 de noviembre, de políticas integrales de juventud, que busca su filiación igualmente en la Agenda 2030, en

\footnotetext{
${ }^{93}$ En dicha Exposición de Motivos puede leerse: "la Declaración del Milenio 2000 y su posterior desarrollo y ampliación en lo relacionado con los objetivos para la igualdad de género y el empoderamiento de las mujeres reflejados en la Agenda 2030 para el Desarrollo Sostenible aprobada por la Asamblea General de Naciones Unidas el 25 de septiembre de 2015, manifiesta que la violencia de género constituye la mayor vulneración de los Derechos Humanos en el mundo y establece la colaboración de los Estados para lograr la erradicación de las desigualdades de género, como uno de los objetivos estratégicos de la actuación de la comunidad internacional”.

${ }^{94}$ Según la Exposición de Motivos de dicha Ley andaluza: "se han celebrado en la última década reuniones anuales de la Conferencia de las Partes (COP) de la Convención Marco de las Naciones Unidas sobre el Cambio Climático (CMNUCC), con el objetivo de tomar decisiones sobre las medidas a adoptar después de 2012, una vez finalizado el primer horizonte temporal del Protocolo de Kioto. Sin resultados satisfactorios en un principio, en la COP21, celebrada del 30 de noviembre al 11 de diciembre de 2015 en París, se llegó a un acuerdo para una acción universal en cambio climático a partir de 2020, acuerdo calificado de histórico por la propia Organización de Naciones Unidas. También en el marco de Naciones Unidas la Asamblea aprobó en septiembre de 2015 la Agenda 2030 para el Desarrollo Sostenible, con 17 objetivos de alcance mundial y de aplicación universal, entre los que se incluye el objetivo específico sobre adopción de medidas urgentes para combatir el cambio climático y sus efectos (objetivo 13)”.

${ }_{95}$ Concretamente, a tenor de dicha Exposición de Motivos, "la Junta de Extremadura se alinea con la Declaración de Quito sobre Ciudades y Asentamientos Humanos Sostenibles para todos en el marco de la Conferencia de Naciones Unidas sobre Vivienda y Desarrollo urbano sostenible (Hábitat III), que se celebró en 2016, para la adopción de la Nueva Agenda Urbana. Esta Agenda contribuye a la implementación y localización de la Agenda 2030 para el Desarrollo Sostenible de manera integral, y para el logro de los Objetivos para el Desarrollo Sostenible (ODS) y sus metas, incluyendo la meta de construir ciudades y asentamientos humanos inclusivos, seguros y sostenibles”.
} 
este caso tanto en el Preámbulo ${ }^{96}$ (el cual halla asimismo base habilitante en los arts. 9.2 y 48 CE, además del art. 49.1.25 del Estatuto de Autonomía) como en el texto articulado $^{97}$. En análoga línea, la Agenda 2030 y los objetivos de erradicación de la pobreza y lucha contra el hambre se ubican en el parte preambular de la Ley 19/2017, de 20 de diciembre, de renta valenciana de inclusión ${ }^{98}$ y de la Ley 5/2018, de 6 de marzo, de la Huerta de València ${ }^{99}$.

Con un enfoque diverso, no en el Preámbulo, pero sí en el texto articulado, se incluye la implementación de la Agenda 2030 en la Ley 18/2018, de 13 de julio, para el fomento de la responsabilidad social, la cual pretende obviamente tener en cuenta los Principios rectores sobre las empresas y los derechos humanos adoptados en 2011 por el Consejo de Derechos Humanos ${ }^{100}$. Pero, sobre todo, con profusa mención de la Agenda 2030 (en más de tres decenas de ocasiones) tanto en el Preámbulo como en el texto articulado, la Ley valenciana 18/2017, de 14 de diciembre, de cooperación y desarrollo sostenible, constituye una especie de norma autonómica tendente a implementar con

\footnotetext{
${ }^{96}$ Según el Preámbulo: "La Agenda 2030 de desarrollo sostenible de Naciones Unidas, adoptada por la Asamblea General de la ONU en septiembre de 2015, que entró en vigor oficialmente el 1 de enero de 2016, establece un plan de acción a favor de las personas, el planeta y la prosperidad, con la intención de fortalecer la paz universal y el acceso a la justicia. En el mundo actual, las personas jóvenes ya no quieren únicamente ser informadas sobre las políticas públicas, los planes y los modelos de desarrollo que les impactan; quieren diseñarlos, tomar las decisiones y ser el vehículo que los implementen. Como jóvenes quieren tener un rol activo mediante el papel principal de la participación juvenil significativa en todos los niveles de toma de decisión, para garantizar un desarrollo sostenible, un crecimiento económico inclusivo, la promoción de sociedades pacíficas y la erradicación de la pobreza”.

${ }^{97}$ Véase art. 5: "Las administraciones públicas se comprometen a: (...) 12. Desarrollar políticas públicas de juventud para involucrar y facilitar la participación activa de la juventud en el proceso de consecución de la Agenda 2030 de Naciones Unidas, en colaboración con el Consejo de la Juventud de España y con cualquier organismo, plataforma, entidad y estructura de participación de los jóvenes en el ámbito de la Unión Europea”.

${ }^{98}$ Además de la referencia a estándares nacionales (constitucionales y autonómicos, entre ellos el art. 17 de la Ley 4/2012, de 15 de octubre, por la que se aprueba la Carta de derechos sociales de la Comunitat Valenciana), europeos (art. 34 de la Carta de los Derechos Fundamentales de la UE) y universales (el art. 25 de la Declaración Universal o el art. 11 del Pacto DESC), con relación a estos últimos se declara: "Cabe resaltar igualmente que mediante la Resolución 70/1, de 25 de septiembre de 2015, de la Asamblea General de Naciones Unidas, por la que se aprueba la Agenda 2030 para el desarrollo sostenible, se fija, entre otros objetivos y metas, el de reducir la desigualdad dentro de los países y entre ellos, y en particular, que desde 2015 a 2030 se debe lograr progresivamente, y mantener el crecimiento de los ingresos del 40\% más pobre de la población a una tasa superior a la media nacional de cada país, y que se debe potenciar y promover la inclusión social, económica y política de todas las personas, independientemente de su edad, sexo, discapacidad, raza, etnia, origen, religión o situación económica u otra condición”.

${ }^{99}$ A tenor del Preámbulo de dicha Ley valenciana 5/2018: "la Asamblea General de la ONU adoptó, el 25 de septiembre 2015, la Agenda 2030 para el desarrollo sostenible, en la que se reconoce que no pueden considerarse por separado la alimentación, los medios de vida y la gestión de los recursos naturales, situando la alimentación y la agricultura en el centro de la misma, ya sea para poner fin a la pobreza y el hambre, para responder al cambio climático o para conservar nuestros recursos naturales. Por eso, adoptar la Agenda 2030 y los objetivos de desarrollo sostenible es esencial para nuestro futuro a largo plazo, y constituyen una referencia obligada en las políticas públicas".

${ }^{100}$ Concretamente, la Ley valenciana 18/2018 dispone, en su art. 10.1 que "las administraciones públicas fomentarán que las entidades de la economía social, las empresas y las organizaciones empresariales de la Comunitat Valenciana puedan contribuir a los esfuerzos de la cooperación para el desarrollo y al cumplimiento de la Agenda 2030 para el desarrollo"; y se cita la Agenda 2030 igualmente en el art. 19.2.e).
} 
carácter general los ODS. En cuanto al Preámbulo, se justifica expresamente que "esta ley, que dicta la Generalitat en el ejercicio de su competencia y potestad de autoorganización, en los términos previstos en los artículos 9, 49.1.1. ${ }^{\mathrm{a}}, 50.1$ y 62 del Estatuto de autonomía de la Comunitat Valenciana, permite articular en un único texto del máximo rango los diferentes elementos que actualmente constituyen la política de la Generalitat en materia de cooperación internacional al desarrollo y, al mismo tiempo, adecuarlos a la realidad y los retos actuales, encaminados a la concreción, profundización y consecución de los Objetivos de Desarrollo Sostenible de la Agenda 2030, procurando la coherencia, coordinación y complementariedad de las actuaciones y su articulación con las prioridades de desarrollo de los territorios donde actúe mediante una cooperación integral” ${ }^{101}$.

En lo que atañe al texto articulado de esa Ley valenciana 18/2017, su primera disposición dispone que “el objeto de esta ley es establecer y regular el régimen jurídico al cual se ha de ajustar la actividad de la administración de la Generalitat y de su sector público dependiente en materia de cooperación internacional al desarrollo y de solidaridad internacional y del cumplimiento de la Agenda 2030 para el Desarrollo Sostenible” (art. 1.1), incidiendo en la "contribución al cumplimiento de los objetivos de desarrollo sostenible de la Agenda 2030, aprobados por Naciones Unidas, sin perjuicio de lo establecido en la legislación estatal en materia de cooperación internacional al

${ }^{101}$ Así, en cuanto a las declaraciones preambulares, pueden leerse estas otras:

-“El contexto de la cooperación internacional al desarrollo viene marcado a partir del año 2015 por un nuevo escenario de retos que ha supuesto la adopción, por la Asamblea General de Naciones Unidas, de la Agenda 2030 para el Desarrollo Sostenible, que significa un cambio de paradigma para el desarrollo. Esta agenda se basa en los logros obtenidos en el marco de la Agenda de los Objetivos de Desarrollo del Milenio (ODM), que orientaron las medidas en pro del desarrollo en el período de 2000 a 2015.

La Agenda 2030 para el Desarrollo Sostenible, integrada por 17 objetivos y 169 metas, constituye el marco para todas las políticas de cooperación y desarrollo, para los instrumentos de financiación y para las alianzas a nivel mundial, estatal, autonómico y local, así como deben serlo aquellas agendas que se aprueben en futuras cumbres mundiales de Naciones Unidas para reafirmar compromisos anteriores y adoptar nuevos objetivos a partir de los logros de los Objetivos de Desarrollo Sostenible”.

-“En particular, la Agenda 2030 de Naciones Unidas reconoce la diversidad del sector privado y menciona a las cooperativas como parte de él, reconociendo su papel en la consecución de los objetivos, consciente de que es imposible el logro de los mismos sin la creatividad y la innovación de la economía social, para resolver los retos del desarrollo sostenible”.

-“Así mismo, esta ley incorpora las resoluciones aprobadas en la Agenda de Acción de Addis Abeba (del 13 al 16 de julio de 2015), la Cumbre del Desarrollo en Nueva York (del 25 al 27 de septiembre de 2015) y la Cumbre del Clima en París (del 30 de noviembre a 11 de diciembre de 2015), que han sido los tres hitos llamados a configurar la Agenda 2030 de Desarrollo Sostenible, o cualquier otro compromiso internacional análogo vigente que en el futuro lo sustituya”.

-“En el título I se recogen los aspectos generales de esta ley, como son el objeto; su ámbito de aplicación, en el que se incorporan los cinco ejes centrales de la Agenda 2030 de Desarrollo Sostenible: personas, planeta, prosperidad, paz y alianzas/partenariado, y los principios para contribuir a su cumplimiento".

-"En el título II (..) se crea el Alto Consejo Consultivo para el Desarrollo de la Agenda 2030, la Comisión Interdepartamental para la Cooperación Internacional al Desarrollo y el Consejo Territorial Sectorial para la Cooperación Internacional al Desarrollo, contemplándose el Consejo Valenciano de Cooperación Internacional al Desarrollo, así como el Comité Permanente de Acción Humanitaria de la Comunitat Valenciana, como órganos consultivos de participación y coordinación”. 
desarrollo” (art. 1.3). A renglón seguido, el art. 2.2 reconduce el ámbito de aplicación de la Ley a "la consecución de los objetivos de la Agenda 2030 para el Desarrollo Sostenible”, lo cual se enfatiza en los apartados 3 y 5 del propio art. 2 y, especialmente, en términos de transversalidad en el apartado $4^{102}$. Se refuerza en el art. 3 de la Ley su objetivo de contribuir al "cumplimiento de la Agenda 2030 para el Desarrollo Sostenible y a la defensa de la Declaración Universal de los Derechos Humanos” (apartado 1), a la “implementación de la Agenda 2030 para el Desarrollo Sostenible” (apartado 3.d), a la “consecución de los Objetivos de la Agenda 2030” (apartado 3.i) y a la "implementación de la Agenda 2030 para el Desarrollo Sostenible y gestión del conocimiento” (apartado $3 . k)^{103}$.

102 Esta es la redacción del art. 2.4 de dicha Ley: "Las políticas y actuaciones que lleven a cabo las administraciones públicas o los agentes de cooperación internacional al desarrollo de la Comunitat Valenciana, en el ámbito de esta ley, incorporarán como propios los cinco ejes centrales de la Agenda 2030 de Desarrollo Sostenible de Naciones Unidas:

a) Personas.

Las llevadas a cabo con la finalidad de poner fin a la pobreza y el hambre en todas sus formas y dimensiones, y de velar por que todos los seres humanos puedan realizar su potencial con dignidad e igualdad y en un medio ambiente saludable.

b) Planeta.

Las llevadas a cabo con la finalidad de proteger el planeta contra la degradación, incluso mediante el consumo y la producción sostenibles, la gestión sostenible de sus recursos naturales y medidas urgentes para hacer frente al cambio climático, de manera que pueda satisfacer las necesidades de las generaciones presentes y futuras.

c) Prosperidad.

Las llevadas a cabo con la finalidad de velar por que todos los seres humanos puedan disfrutar de una vida próspera y plena, y de que el progreso económico, social y tecnológico se produzca en armonía con la naturaleza.

d) Paz.

Las llevadas a cabo con la finalidad de propiciar sociedades pacíficas, justas e inclusivas que estén libres del temor y la violencia. El desarrollo no es posible sin la paz, ni la paz puede existir sin el desarrollo sostenible.

e) Alianzas/partenariado.

Las llevadas a cabo con la finalidad de movilizar los medios necesarios para desarrollar y promover la Agenda 2030 mediante una alianza mundial para el desarrollo revitalizada, que se base en un espíritu de mayor solidaridad mundial y se centre particularmente en las necesidades de las gentes más pobres y vulnerables, con la colaboración de todos los países, todas las partes interesadas y todas las personas”.

${ }^{103}$ En idéntica dirección, se reitera explícitamente esa idea de implementación de la Agenda 2030 en el art. 10 [apartados 1.c) y e), y 2], en el art. 12 (que regula el cometido del Alto Consejo Consultivo para el Desarrollo de la Agenda 2030), en el art. 13 (Comisión Interdepartamental para la Cooperación Internacional al Desarrollo), en el art. 15 (Consejo Territorial Sectorial para la Cooperación Internacional al Desarrollo), en el art. 26 (en cuyo apartado 2 donde se cifra la participación de las cooperativas, las empresas y las asociaciones empresariales de la Comunitat Valenciana en la cooperación y el desarrollo sostenible en "educación y sensibilización para el cumplimiento de la Agenda 2030 entre el empresariado valenciano”), en el art. 27 (en cuyo apartado 2 se cifra asimismo la participación de las organizaciones sindicales de la Comunitat Valenciana en la cooperación internacional al desarrollo en "educación y sensibilización para el cumplimiento de la Agenda 2030 entre los trabajadores y trabajadoras valencianos”) y, por último, en la disposición final segunda (desarrollo reglamentario para, entre otros ámbitos, "la consecución de los Objetivos de Desarrollo Sostenible de la Agenda 2030 de Naciones Unidas en la Comunitat Valenciana”). 


\section{Consideraciones finales: los ODS como reto del constitucionalismo global y multinivel.}

Como se anticipó, algunos de los ODS revisten una ostensible naturaleza transversal en pro de la igualdad (objetivo 10), la solidaridad y la justicia (objetivo 16) ${ }^{104}$ como ejes de un nuevo constitucionalismo global social que posibilitará la efectividad de todos los ODS a través una "alianza mundial para el desarrollo sostenible” (objetivo 17), tanto más cuanto que "la realidad globalizadora obliga a la puesta en práctica, de forma urgente, de una verdadera integración mundial fundada en la justicia y el derecho” ${ }^{105}$. Ahora bien, parece que la globalización económica sigue teniendo todavía mayor robustez que ese constitucionalismo global inspirado por los ODS ${ }^{106}$.

En este contexto, al margen del valor interpretativo de los ODS en sede jurisdiccional, sea ordinaria o constitucional, ello no debe conducir a una obsesión en clave de justiciabilidad de los derechos sociales, lo cual supondría un enfoque reduccionista del constitucionalismo social con una visión alicorta de la efectividad de los derechos sociales, cuya vigencia ha de lograrse primordialmente por la acción espontánea de las personas afectadas, el soporte de las organizaciones de la sociedad civil y la actividad de todos los poderes públicos (normativa y administrativamente), en el sentido del art. 53.3 CE.

En otras palabras, los apuntes ofrecidos de la jurisprudencia del TC y de otros órganos jurisdiccionales ordinarios (epígrafe II, supra) no deben hacer perder de vista su papel subsidiario, de tal modo que su intervención será tanto menos importante cuanto mayor sea el impacto orientador de los ODS a través de su desarrollo normativo y su implementación por parte de los focos de poder legislativos y ejecutivos nacionales, respectivamente (epígrafe III, supra). Al hilo de lo precedente, el carácter formalmente no vinculante de los ODS se ve compensado de esta forma con los actos normativos

\footnotetext{
${ }^{104}$ Con el objetivo 10 se pretende "reducir la desigualdad en los países y entre ellos” y con el 16 "promover sociedades pacíficas e inclusivas para el desarrollo sostenible, facilitar el acceso a la justicia para todos y construir a todos los niveles instituciones eficaces e inclusivas que rindan cuentas”.

105 JÁUREGUI BERECIARTU, G.: “Globalización, Unión Europea y Gobernanza Multinivel: El rol de la UE en el rediseño de un orden político mundial más justo e igualitario”, en el colectivo Peligros actuales para la Unión Europea, Donostia/San Sebastián, Eurobask. Consejo Vasco del Movimiento Europeo, 2015, p. 22.

106 Sobre el particular, ha observado ESCOBAR ROCA, G.: Nuevos derechos y garantías de los derechos, Madrid, Marcial Pons, 2018, p. 82-83: "La globalización ha aumentado notablemente, inclusive en materia de derechos, aunque en un plano en la práctica menor en comparación con la globalización económica. Se diría incluso que se ha producido , al menos en parte, un cierto conflicto entre dos globalizaciones que simplificadamente pueden explicarse como sigue: por un lado el aumento de las transacciones económicas internacionales se ha realizado al margen del Derecho (o, al menos, de normas claramente establecidas) y ha afectado negativamente a algunos derechos; por otro, la comunidad internacional ha llamado la atención sobre este problema y ha intentado paliarlo, aunque tímidamente y con escaso éxito. Tampoco las llamadas a una mayor solidaridad entre las naciones han encontrado adecuado reflejo en los textos constitucionales. En espera de un constitucionalismo mundial, que de momento apenas se ha iniciado, las Constituciones nacionales podrían ir avanzando: por ejemplo, reconociendo la competencia de tribunales u organismos internacionales de garantía de los derechos, la justicia universal, la aplicación extraterritorial, cuando sea posible, de algunos derechos fundamentales, o la cooperación al desarrollo”.
} 
nacionales obligatorios de desarrollo de esa Agenda 2030 (de nuevo, epígrafe III, supra), que juegan a modo de mediación eficaz y vinculante.

Lo mismo podría predicarse de los actos normativos vinculantes que se adopten a nivel europeo para la implementación de la Agenda 2030. Sobre este punto, al margen de la considerada realmente como Constitución Social Europea o Pacto Europeo de Democracia Social (la Carta Social Europea del Consejo de Europa, revisada en 1996), en el marco de la UE debe tomarse como referencia el Pilar Europeo de Derechos Sociales proclamado en la Cumbre de Gotemburgo en noviembre de 2017. En la Proclamación institucional de dicho Pilar ${ }^{107}$, concretamente en el apartado 1 del Preámbulo, se incluye una referencia al "desarrollo sostenible de Europa" ${ }^{108}$, lo cual engarza claramente con la implementación de los ODS, como se confirma en el Documento de trabajo de los servicios de la Comisión Europea sobre el citado Pilar ${ }^{109}$.

Habrá que esperar para comprobar si, en la puesta en práctica del Pilar Europeo, las acciones de la UE son coherentes con los ODS y los atienden de acuerdo con la idea de estándar más favorable (principio favor libertatis o pro personae) contemplada en el párrafo 16 del Preámbulo del propio Pilar Europeo, el cual evoca el contenido del art. 53 de la Carta de los Derechos Fundamentales de la Unión Europea ${ }^{110}$. En todo caso, ese

\footnotetext{
${ }^{107}$ Véase el texto oficial de la Proclamación interinstitucional sobre el Pilar Europeo de Derechos Sociales por parte del Parlamento Europeo, el Consejo y la Comisión, en el DOUE de 13 de diciembre de 2017 (2017/C 428/09).

${ }^{108}$ Concretamente, ese primer párrafo del Preámbulo declara: "De conformidad con el artículo 3 del Tratado de la Unión Europea, los objetivos de la Unión son, entre otros, promover el bienestar de sus pueblos y obrar en pro del desarrollo sostenible de Europa basado en un crecimiento económico equilibrado y en la estabilidad de los precios, en una economía social de mercado altamente competitiva, tendente al pleno empleo y al progreso social, y en un nivel elevado de protección y mejora de la calidad del medio ambiente. La Unión debe combatir la exclusión social y la discriminación y fomentar la justicia y la protección sociales, la igualdad entre mujeres y hombres, la solidaridad entre las generaciones y la protección de los derechos del niño".

${ }^{109}$ Documento SWD(2017) 201 final, Bruselas, 26 de abril de 2017. Se dice así en el párrafo segundo de la Introducción de dicho Documento: "El pilar se basa en el corpus jurídico existente tanto en el contexto de la UE como internacional. En concreto, el pilar se basa en la Carta Comunitaria de los Derechos Sociales Fundamentales de los Trabajadores 1989, la Carta Social Europea de 1961, la Carta Social Europea en su versión revisada de 1996 y el Código Europeo de la Seguridad Social del Consejo de Europa. Los principios tienen en cuenta también los correspondientes convenios, recomendaciones y protocolos asociados de la Organización Internacional del Trabajo (OIT), así como la Convención de las Naciones Unidas sobre los derechos de las personas con discapacidad. Por otra parte, en los últimos treinta años también se ha desarrollado el acervo social de la UE, por medio de nuevas disposiciones en los Tratados de la UE, la adopción de la Carta de los derechos fundamentales de la Unión Europea, nueva legislación y la jurisprudencia del Tribunal de Justicia de la Unión Europea. Más recientemente, la adopción de los Objetivos de Desarrollo Sostenible de las Naciones Unidas para 2030 ha proporcionado una nueva agenda para hacer frente a la erradicación de la pobreza, así como a las dimensiones económica, social, de solidaridad y de medio ambiente del desarrollo sostenible de forma equilibrada e integrada".

${ }^{110}$ El párrafo 16 del Preámbulo del Pilar dice: "El pilar europeo de derechos sociales no debe impedir que los Estados miembros o sus interlocutores sociales establezcan normas sociales más ambiciosas. En particular, ninguna de las disposiciones del pilar europeo de derechos sociales debe poder interpretarse como limitativa o lesiva de los derechos y principios reconocidos, en su respectivo ámbito de aplicación, por el Derecho de la Unión o por el Derecho internacional y por los convenios internacionales de los que son parte la Unión o los Estados miembros, incluida la Carta Social Europea, firmada en Turín el 18 de octubre de 1961, y los convenios y recomendaciones de la Organización Internacional del Trabajo”.
} 
principio nos permite concatenar las cuestiones procedimentales y sustanciales relativas a la efectividad constitucional de los ODS analizados en el bloque central del presente trabajo (epígrafes II y III).

A la vista de lo recién expuesto, a mi entender cabe sostener que los ODS se erigen, mutatis mutandis, en una especie de Pilar Universal de los Derechos Sociales que propende a la mundialización de la democracia social. Tal como se vislumbra en la Agenda 2030, la profundización en la democracia y consiguiente participación ciudadana pone en juego asimismo el ejercicio de los derechos sociales, puesto que la pobreza digital conduce a una brecha digital ${ }^{111}$ que, a su vez, genera riesgos de exclusión de la democracia electrónica, convirtiendo en escenarios meramente cosméticos las actuales proclamas de buen gobierno, acceso a la información pública y transparencia, por más que estén respaldadas formalmente por normativa nacional e internacional. Como acertadamente se advirtió en la doctrina, "no se necesita demasiada sagacidad para darse cuenta de que, en la época del constitucionalismo social, y al igual que sucediera en los tiempos del constitucionalismo liberal, los desajustes y contradicciones entre los principios y supuestos definidores del Estado y la propia realidad estatal son abismales y escandalosos" y, por ello mismo, deben afrontarse tales desfases en clave de mundialización del Derecho constitucional ${ }^{112}$.

Desde esta óptica, las referidas claves del modelo democrático constituyen un reto para el constitucionalismo social que trasciende la realidad del Estado y se entrelaza con los ODS ${ }^{113}$. Los constitucionalistas, sobre todo a través de la enseñanza y la educación (y de la investigación universitaria) ${ }^{114}$, tenemos una responsabilidad especial a la hora de contribuir a consolidar el sentimiento constitucional ${ }^{115} \mathrm{y}$, teniendo ello en mente, los ODS

\footnotetext{
${ }^{111}$ Véase asimismo el párrafo 15 de la Declaración incluida en la Resolución de 2015 sobre los ODS.

${ }^{112}$ DE VEGA GARCÍA, P.: "Mundialización y Derecho constitucional: la crisis del principio democrático en el constitucionalismo actual”, Revista de Estudios Políticos, nº 100, 1998, p. 46.

${ }^{113}$ SARLET, I.W.: "Los derechos sociales en el constitucionalismo contemporáneo: algunos problemas y desafíos”, en PRESNO LINERA, M.A., y SARLET, I.W. (Eds.): Los Derechos Sociales como Instrumento de Emancipación, Cizur Menor, Thomson/Aranzadi, , p. 60-61: al abordar la vigencia del modelo democrático, el citado autor lo pone en conexión con instrumentos efectivos de participación ciudadana, "de modo que la llamada inclusión digital suma un papel de creciente importancia también para los derechos sociales. Además, es posible sostener la existencia de un derecho fundamental a prestaciones en este ámbito, asegurando las condiciones mínimas de acceso al mundo digital y a sus posibilidades. Tales desafíos, aunque no agoten las posibilidades, muestran bien que la problemática de los derechos sociales, especialmente en tanto están comprendidos en una perspectiva más amplia e integrada en los demás derechos fundamentales, tiene actualidad y es relevante para el presente y el futuro del constitucionalismo y, por tanto, del modelo de Estado constitucional y democrático de derecho, y de la comunidad internacional”.

${ }^{114}$ Con tal filosofía, SALVIOLI, F.O.: La universidad y la educación en el siglo XXI, San José de Costa Rica, Instituto Interamericano de Derechos Humanos, 2009, p. 335: tras incidir en la interrelación entre la democracia y los derechos humanos, el citado autor enfatiza que "el desarrollo de la investigación universitaria también posee vinculaciones muy importantes con los derechos y libertades fundamentales de mujeres y hombres".

115 TAJADURA TEJADA, J.: El Derecho Constitucional y su enseñanza, Lima, Grijley/Instituto Iberoamericano de Derecho Constitución (Sección Peruana), 2001, p. 118. Más recientemente, y tras subrayar la "trascendencia técnico-jurídica" del Preámbulo constitucional, ha recordado ALZAGA VILLAAMIL, O.: "Preámbulo", en PÉREZ TREMPS, P., y Alejandro SÁIZ ARNAIZ, A. (Dirs):
} 
constituyen una Agenda de constitucionalismo global insoslayable para nutrir dicho sentimiento en paralelo a una conciencia internacional favorable al respeto de la dignidad humana y a la perennidad o sostenibilidad de unos valores e ideas que, sin desprecio del pluralismo cultural y de las conciencias nacionales ${ }^{116}$, sea germen de consensos universales (a través de una especie de humanismo ecuménico en acción) ${ }^{117}$ en torno a la salvaguardia del Estado de Derecho, de la Democracia y los Derechos Humanos ${ }^{118}$.

Comentario a la Constitución Española: 40 aniversario 1978-2018. Libro-homenaje a Luis López Guerra, Tomo I (Preámbulo a Artículo 96), Valencia, Tirant lo Blanch, 2018, p. 102: “el Preámbulo de nuestra Constitución se aprobó con el propósito de hacer llegar a la ciudadanía unas importantes ideas fuerza que sirven de cimientos a la Constitución. Se escribió bien por Pablo Lucas Verdú que el Preámbulo puede contribuir a crear el sentimiento constitucional, entendido como vínculo moral que une a los ciudadanos con sus instituciones, siempre que aquellos asuman los principios constitucionales como elemento irrenunciable de la convivencia. El Preámbulo así entendido es un factor jurídico de integración de la comunidad”.

${ }^{116}$ En este panorama, expresó BORRERO CABRAL, A.: L'Université aujourd'hui, Paris, UNESCO, 1995, p. 38: "En un mundo en el que la internacionalización se acelera y en una época en la que las grandes empresas transnacionales tienen ambiciones que desbordan la esfera económica y comercial, resulta plausible y loable que, sin hacer tabla rasa del pasado, la conciencia nacional refleje un nuevo concepto de soberanía nacional. La conciencia de los derechos ecológicos de las generaciones futuras es una expresión de ello".

${ }^{117}$ Así lo etiquetó SCHAFF, A.: Humanismo ecuménico, Madrid, Trotta, 1993, p. 89: "La conclusión de que es necesaria una colaboración de los dos grandes humanismos de nuestro tiempo -el socialista y el cristiano- surge de la visión aquí presentada sobre la evolución social en la era de la revolución industrial, así como de las consiguientes exigencias, también en el campo de los valores, que motivan al hombre a transformar los mecanismos sociales existentes. Se trata de la interiorización de estos valores por parte de la sociedad, lo que permitiría realizar un paso hacia una nueva condición de vida, no sólo en el sentido de un mayor bienestar, sino también en democracia y libertad. (...) De ahí la necesidad real de una alianza de los humanismos".

${ }^{118}$ Por supuesto, entre el espacio global y el estatal, en el ámbito regional resulta esencial seguir forjando la cultura de los derechos como complementario exponente de "identidad europea”, como bien ha analizado PÉREZ DE LAS HERAS, B.: “The Charter of Fundamental Rights as a new Element of European Identity and Beyond”, en PÉREZ DE LAS HERAS, B. (Ed.): Democratic Legitimacy in the European Union and Global Gobernance. Building a European Demos, London, Palgrave Macmillan, 2017, p. 127. 